\title{
Note to readers
}

For the definitive version of this paper, see:

Moghaddasi, M., Cubrinovski, M., Chase, G.J., Pampanin, S. and Carr, A. (2011) Probabilistic evaluation of soil-foundation-structure interaction effects on seismic structural response.

Earthquake Engineering and Structural Dynamics, 40(2), 135-154.

http://dx.doi.org/10.1002/eqe.1011.

+ This article was published online on [29 April 2010]. An error was subsequently identified. This notice is included in the online and print versions to indicate that both have been corrected [28 May 2010]. 


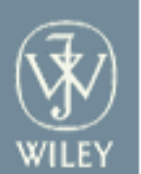

Earthquake Engineering and Structural Dynamics

\section{Probabilistic Evaluation of Soil-Foundation-Structure Interaction Effects on Seismic Structural Response}

\begin{tabular}{|c|c|}
\hline Journal: & Earthquake Engineering and Structural Dynamics \\
\hline Manuscript ID: & EQE-09-0338 \\
\hline Wiley - Manuscript type: & Research Article \\
\hline $\begin{array}{r}\text { Date Submitted by the } \\
\text { Author: }\end{array}$ & 24-Dec-2009 \\
\hline Complete List of Authors: & $\begin{array}{l}\text { Moghaddasi Kuchaksarai, Masoud; University of Canterbury, } \\
\text { Department of Civil and Natural Resources Engineeirng } \\
\text { Cubrinovski, Misko; University of Canterbury, Civil Engineering } \\
\text { Chase, J.; University of Canterbury, Mechanical Engineering } \\
\text { Pampanin, Stefano; University of Canterbury, Department of Civil } \\
\text { Engineering } \\
\text { Carr, Athol; University of Canterbury, Civil Engineering }\end{array}$ \\
\hline Keywords: & $\begin{array}{l}\text { Soil-Foundation-Structure-Interaction, Monte Carlo Simulation, } \\
\text { Earthquake Ground Motion, Nonlinear Behaviour, Probability }\end{array}$ \\
\hline
\end{tabular}

\section{s ScholarONE" \\ Manuscript Central}




\title{
Probabilistic Evaluation of Soil-Foundation- Structure Interaction Effects on Seismic Structural Response
}

\author{
M. Moghaddasi K. ${ }^{1 *}$, M. Cubrinovski ${ }^{1}$, J.G. Chase ${ }^{2}$, S. Pampanin ${ }^{1}$, \\ A. Carr $^{1}$ \\ ${ }^{1}$ Department of Civil and Natural Resources Engineering, University of Canterbury, Private Bag \\ 4800, Christchurch 8140, New Zealand, Tel. (+64) 3-364-2250 \\ ${ }^{2}$ Mechanical Engineering Department, University of Canterbury, Private Bag 4800, \\ Christchurch 8140, New Zealand, Tel. (+64) 3-364-2596
}

\begin{abstract}
Complex seismic behaviour of soil-foundation-structure (SFS) systems together with uncertainties in system parameters and variability in earthquake ground motions result in a significant debate over the effects of soil-foundation-structure interaction (SFSI) on structural response. The aim of this study is to evaluate the influence of foundation flexibility on the structural seismic response by considering the variability in the system and uncertainties in the ground motion characteristics through comprehensive numerical simulations. An established rheological soil-shallow foundation-structure model with equivalent linear soil behaviour and nonlinear behaviour of the superstructure has been used. A large number of models incorporating wide range of soil, foundation and structural parameters were generated using a robust Monte Carlo simulation. In total, 4.08 million time-history analyses were performed over the adopted models using an ensemble of 40 earthquake ground motions as seismic input. The results of the analyses

\footnotetext{
${ }^{I}$ Corresponding author. Tel. (+64) 3-364-2250.

E-mail address: masoud.moghaddasi@pg.canterbury.ac.nz
} 
are used to rigorously quantify the effects of foundation flexibility on the structural distortion and total displacement of the superstructure through comparisons between the responses of SFS models and corresponding fixed-base models. Effects of predominant period of the fixed-base system, linear vs. non-linear modelling of the superstructure, type of nonlinear model used and key system parameters are quantified in terms of different probability levels for SFSI effects to cause an increase in the structural response and the level of amplification of the response in such cases. The results clearly illustrate the risk of underestimating the structural response associated with simplified approaches in which SFSI and nonlinear effects are ignored.

Keywords: Soil-Foundation-Structure-Interaction, Monte Carlo Simulation, Earthquake Ground Motion, Nonlinear Behaviour, Probability

\section{INTRODUCTION}

The seismic behaviour of soil-foundation-structure (SFS) systems is very complex involving inherent uncertainties in system properties, nonlinear behaviour and ground motion characteristics, and hence, the difficulty in assessing the effects of seismic soilfoundation-structure interaction (SFSI) on the structural response. Conventionally, the seismic response of structures taking into account SFSI effects is approximated by modifying the predominant period and associated damping of the corresponding fixedbase (FB) system [1-3]. Even though the nonlinear behaviour of the superstructure is not considered, this approach forms the basis of the seismic design provisions currently in use [4-7] and essentially asserts that including SFSI in the analysis will have a beneficial effect (or reduction) in the seismic response of structures. 
Contradicting this prevailing view, however, recent evidence suggests that this perceived beneficial role of SFSI is an unconservative oversimplification for certain seismic events and soil-structure systems [8-11]. This lack of clarity in the SFSI effects on the seismic response of structures is even more pronounced when nonlinear behaviour of the superstructure is considered. For example, it is stated that structural yielding increases the flexibility of the soil-foundation-structure system and thus, assists the beneficial role of SFSI $[12,13]$. In contrast, it is also argued that the ductility demand may be increased significantly due to the impact of foundation flexibility $[14,15,16]$. Interestingly, there are few studies showing that SFSI effects are not significant when inelastic response of the superstructure is considered $[17,18]$.

Considering all these somewhat contradictory findings, further studies are needed to rigorously evaluate the inertial SFSI effects on seismic responses of structures while accounting for the abovementioned uncertainties and nonlinear behaviour. A rational way for achieving this is to make use of a comprehensive probabilistic evaluation which is an approach gaining growing attention in the geotechnical engineering community [19] and investigation of SFSI effects [20-24]. This study aims at investigating the complex dynamic inertial SFSI problem through a robust Monte Carlo simulation and quantifying the influence of foundation flexibility on the structural seismic response. The emphasis is placed on covering, (i) a wide range of randomly generated models of realistic and representative SFS systems, and (ii) earthquake ground motions with different characteristics, to develop structural response modification spectrum similar to that used in the design spectra analysis.

To make this Monte-Carlo simulation feasible, an idealized, but commonly used, soil-shallow foundation-structure model was adopted following the current design 
practice. In this model: (i) the superstructure is represented by a single-degree-offreedom (SDOF) system with 5\% equivalent viscous damping and linear or nonlinear (bilinear elastic-plastic or Takeda degrading stiffness model) load-displacement relationship; and (ii) the soil-foundation part was represented by an equivalent linear cone model [25] accounting for nonlinearity in the stress-strain behaviour of soils [26]. This interaction model, although simple, ensures a wide applicability of results since it satisfies various requirements stipulated in building codes [4-7]. The adopted MonteCarlo simulation procedure provided systematic means for addressing the uncertainties in soil, structure, SFS system parameters and earthquake motion characteristics though a comprehensive set of 4.08 million time history analyses.

The SFSI effects on the structural response are quantified and compared using a robust statistics called interquartile range (IQR), which is a simple graphical representation of probability distribution of the outcomes. Following this quantification, the likelihood of SFSI scenarios with detrimental effects (or increase) in the structural response is presented along with the level of increase in the response for such scenarios. The link between SFSI effects and various system parameters is examined and rigorously quantified.

Respecting the scope of this probabilistic study, the presented outcomes are mostly to highlight the SFSI effects on structural seismic response but not to provide the complete solutions to the problem. 


\section{SOIL-SHALLOW FOUNDATION-STRUCTURE MODEL}

\subsection{Specifications of the adopted dynamic model}

A fairly simple SFS model shown in Figure 1 was adopted for dynamic time-history analysis. In the model, the superstructure is represented by a single-degree-of-freedom (SDOF) system linked by a rigid beam to a shallow foundation, which is resting on a soil deposit. The mass of the foundation and the mass moment of inertia of the superstructure are neglected [27]. For this model, 3 global and 1 internal degrees of freedom are defined:

$\mathrm{u}_{0}$ : horizontal displacement of foundation relative to the free-field ground

$\mathrm{u}_{\varphi}$ : rocking motion of foundation

u: structural distortion (horizontal displacement of superstructure relative to foundation)

$\mathrm{u}_{\varphi 1}$ : internal rocking motion

SDOF Superstructure: The idealized SDOF can be interpreted as an equivalent representation of the fundamental mode of vibration of a fixed-base (FB) multi-storey structure. This SDOF structural representation is characterized by: (i) structural mass participating in the fundamental mode of vibration, $m_{s t r}$, (ii) structural lateral stiffness, $k_{s t r}$, (iii) $5 \%$ equivalent viscous structural damping, $\xi$, and (iv) effective height considered from the foundation level to the centre of the structural mass, $h_{\text {eff. }}$ As shown in Figure 2, three different models (linear, Takeda degrading stiffness and bilinear elastic-plastic) were used to represent the force-deflection behaviour of the superstructure. The linear model was used to develop a conceptual understanding of SFSI effects on structural seismic response and as a benchmark reference for the effects 
of structural nonlinearity. The Takeda degrading stiffness model (TKDS) and bilinear elastic-plastic model (BLEP) were selected to represent the behaviour of concreteframed and steel-framed structures, respectively.

Soil-Foundation Element: The soil-foundation element was modelled by an equivalent linear discrete element based on rheological cone model with frequencyindependent coefficients and equivalent linear method. Cone model [25] represents a shallow foundation with a radius $r$ resting on a homogeneous linear elastic half-space. The stiffness of the supporting soil medium is represented by springs, while the dissipation of the energy is accounted for by the dashpots. In this study, only horizontal and rocking motions of the foundation were considered and since the foundation is located on the ground surface, the horizontal and rocking degrees of freedom were modelled independently. The coefficients used to define this soil-foundation model include: (i) horizontal stiffness, $k_{0}$, (ii) rocking stiffness, $k_{\varphi}$, (iii) horizontal damping, $c_{0}$, (iv) rocking damping, $c_{\varphi}$, and ( $v$ ) internal mass moment of inertia, $m_{\varphi}$, which are summarized in Table 1. To modify the effect of soil incompressibility, an additional mass moment of inertia, $\Delta m_{\varphi}$, is utilized at the foundation level. Moreover, soil material damping is covered using the classical Voigt model of viscoelasticity [25] wherein to avoid further complications in time-domain analyses, the damping was assumed to be viscous instead of hysteretic. This viscous damping was implemented in the soilfoundation element through augmenting each original elastic spring $k_{i}$ by an additional parallel connected dashpot $\bar{c}_{i}=2 k_{i}\left(\xi_{0} / \omega_{0}\right)$. and each original elastic dashpot $c_{i}$ by an additional parallel connected inertial mass $\bar{m}_{i}=c_{i}\left(\xi_{0} / \omega_{0}\right)$. Herein, $\xi_{0}$ defines the material damping of the soil and $\omega_{0}$ is the effective frequency of the SFS system [28]. 
Equations of Motions: Since kinematic interaction is zero for shallow foundations, an acceleration time-history (earthquake record in the free-field), $\ddot{u}_{g}(t)$, was directly used as an input at the foundation level. To formulate the dynamic equations of motion of the considered SFS model, the total horizontal displacement of the structure, $u_{t}$, was expressed as a sum of four components:

$$
\mathrm{u}_{\mathrm{t}}(\mathrm{t})=\mathrm{u}_{\mathrm{g}}(\mathrm{t})+\mathrm{u}_{0}(\mathrm{t})+\mathrm{hu} \mathrm{u}_{\varphi}(\mathrm{t})+\mathrm{u}(\mathrm{t})
$$

Following this decomposition, the equations of motion can be established as follows:

$$
[\mathrm{M}]\{\ddot{\mathrm{u}}\}+[\mathrm{C}]\{\dot{\mathrm{u}}\}+[\mathrm{K}]\{\mathrm{u}\}=\{\mathrm{F}\}
$$

where $[\mathrm{M}],[\mathrm{C}],[\mathrm{K}]$ are the mass, damping and stiffness matrices respectively, and $\{\mathrm{F}\}$ is a force vector. They are defined as:

$$
\begin{aligned}
& {[\mathrm{M}]=\left[\begin{array}{cccc}
\mathrm{m}_{\mathrm{str}} & \mathrm{m}_{\mathrm{str}} & \mathrm{m}_{\text {str }} \mathrm{h}_{\text {eff }} & 0 \\
\mathrm{~m}_{\mathrm{str}} & \left(\mathrm{m}_{\mathrm{str}}+\mathrm{c}_{0} \frac{\xi_{0}}{\omega_{0}}\right) & \mathrm{m}_{\mathrm{str}} \mathrm{h}_{\text {eff }} & 0 \\
\mathrm{~m}_{\mathrm{str}} \mathrm{h}_{\mathrm{eff}} & \mathrm{m}_{\mathrm{str}} \mathrm{h}_{\mathrm{eff}} & \left(\mathrm{m}_{\mathrm{str}} \mathrm{h}_{\mathrm{eff}}^{2}+\Delta \mathrm{m}_{\varphi}+\mathrm{c}_{\varphi} \frac{\xi_{0}}{\omega_{0}}\right) & -\mathrm{c}_{\varphi} \frac{\xi_{0}}{\omega_{0}} \\
0 & 0 & -\mathrm{c}_{\varphi} \frac{\xi_{0}}{\omega_{0}} & \left(\mathrm{~m}_{\varphi}+\mathrm{c}_{\varphi} \frac{\xi_{0}}{\omega_{0}}\right)
\end{array}\right]} \\
& {[\mathrm{C}]=\left[\begin{array}{ccccc}
\mathrm{c}_{\mathrm{str}} & 0 & 0 & 0 \\
0 & \left(\mathrm{c}_{0}+2 \mathrm{k}_{0} \frac{\xi_{0}}{\omega_{0}}\right) & 0 & 0 \\
0 & 0 & \left(2 \mathrm{k}_{\varphi} \frac{\xi_{0}}{\omega_{0}}+\mathrm{c}_{\varphi}\right) & -\mathrm{c}_{\varphi} \\
0 & 0 & -\mathrm{c}_{\varphi} & \mathrm{c}_{\varphi}
\end{array}\right] \quad[\mathrm{K}]=\left[\begin{array}{cccc}
\mathrm{k}_{\mathrm{str}} & 0 & 0 & 0 \\
0 & \mathrm{k}_{0} & 0 & 0 \\
0 & 0 & \mathrm{k}_{\varphi} & 0 \\
0 & 0 & 0 & 0
\end{array}\right]} \\
& \{\mathrm{F}\}=-\left\{\begin{array}{c}
\mathrm{m}_{\mathrm{str}} \\
\mathrm{m}_{\mathrm{str}}+\mathrm{c}_{0} \frac{\xi_{0}}{\omega_{0}} \\
\mathrm{~m}_{\mathrm{str}} \mathrm{h}_{\text {eff }} \\
0
\end{array}\right\} \ddot{\mathrm{u}}_{\mathrm{g}} \quad\{\mathrm{u}\}=\left\{\begin{array}{c}
\mathrm{u}_{\mathrm{str}} \\
\mathrm{u}_{0} \\
\mathrm{u}_{\varphi} \\
\mathrm{u}_{\varphi 1}
\end{array}\right\}
\end{aligned}
$$

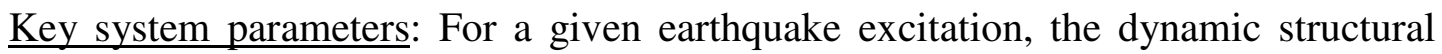
response depends on the properties of the superstructure relative to those of the soil and 
foundation. For the adopted SFS model, the effect of structural and soil parameters is evaluated through the following dimensionless system parameters $[2,25,28]$ :

$\tilde{h}=h_{\text {eff }} / r:$ structural aspect ratio

$\tilde{m}=m_{s t r} / \rho r^{3}:$ structure-to-soil mass ratio

$\tilde{\omega}=\omega_{s t r} h_{e f f} / V_{s}:$ structure-to-soil stiffness ratio (here $\omega_{s t r}$ is circular frequency of the fixed-base superstructure)

\subsection{Incorporating soil nonlinearity in soil-foundation element}

To incorporate soil nonlinearity into the soil-foundation element, the conventional equivalent linear method was utilized [29]. This approach is based on approximating the nonlinear stress-strain curve of soil by a secant stiffness, $G_{s e c}$, and an equivalent damping, $\xi_{e q}$, that are compatible with the strain in the soil induced by the ground shaking. The equivalent linear approach is schematically illustrated in Figure 3, where at a given shear strain level, $\gamma$, the nonlinear stress-strain curve and corresponding hysteretic damping are represented by $G_{s e c}$, and $\xi_{e q}$. By introducing $G_{s e c}$, or respective shear wave velocity, $V_{\text {sec }}=\left(G_{s e d} \rho\right)^{1 / 2}$, and corresponding $\xi_{e q}$ in the cone model (expressions in Table 1), stiffness degradation and increasing damping due to soil nonlinear behaviour are incorporated into the SFS model.

\section{PROCEDURE FOR PROBABILISTIC ANALYSES}

\subsection{General procedure}

While the analysis of this SFS model is relatively straightforward, significant uncertainties in model parameters and ground motion characteristics can result in a wide 
range of responses of the system. A rigorous evaluation of the response of the SFS system requires:

1- Identification, quantification and modelling of the sources of uncertainty

2- Computation of the structural response for a wide range of realistic scenarios

3- Assessment of SFSI effects on the structural response and their likelihood of occurrence

The approach adopted in this study was to systematically compute the seismic response for a wide range of realistic SFS models when subjected to various earthquake excitations with different ground motion characteristics. A robust Monte-Carlo simulation was used to generate models through random selection procedure as outlined below:

(i) Seventeen groups of models were defined for 17 fundamental periods of corresponding fixed-base superstructure, $T_{F B}$, in the range between 0.2 and $1.8 \mathrm{sec}$, with a period increment of $0.1 \mathrm{sec}$. This period set was selected to represent superstructures 3-30 $\mathrm{m}$ high and to satisfy the period-height relationship stipulated in the New Zealand Standard (NZS1170.5) [30].

(ii) For each of these 17 groups, 1000 models constrained to conform to the adopted $\mathrm{T}_{\mathrm{FB}}$ and to produce realistic SFS models, were randomly generated. A relatively large number of 1000 models were chosen in order to provide: (i) a uniform distribution for the randomly selected parameters (Figure 4) and (ii) high level of accuracy of the Monte-Carlo simulation [31].

All SFS models along with their corresponding FB models were then analysed using a nonlinear FEM code “Ruaumoko 2D” [32]. Each model was subjected to 40 different ground motions. The results of the time-history analyses are presented herein in terms 
of a normalized response of the adopted SFS models with respect to the response of the corresponding FB models using statistical measures such as the central tendency and associated dispersion.

\subsection{Selection of soil parameters}

All soil parameters defining the soil-foundation element were considered as uncertain parameters. Initial soil shear wave velocity, $\left(V_{s}\right)_{0}$, shear wave velocity degradation ratio, $\left(V_{s}\right)_{\text {sed }}\left(V_{s}\right)_{0}$, where $\left(V_{s}\right)_{\text {sec }}$ represents the degraded shear wave velocity, soil mass density, $\rho$, and Poisson's ratio $v$ were defined as independent parameters; for each of them, a realistic range was defined first, and then 1000 uniformly distributed values were assigned to that range. The variation range of $80-360 \mathrm{~m} / \mathrm{sec}$ was chosen for $\left(V_{s}\right)_{0}$ to represent stiff/soft soils (type C and D based on USGS classification). This initial shear wave velocity, as mentioned in Section 2.2, was degraded to account for the nonlinear effects of soil behaviour. Assuming that the shear strain induced in the soil is within the range of $0.01-1 \%,\left(V_{s}\right)_{s e c} /\left(V_{s}\right)_{0}$ ratio was adopted in the range between 0.15 and 0.7 based on conventional modulus reduction curves [33]. For $\rho$ and $v$, variation ranges of 1.6-1.9 ton $/ \mathrm{m}^{3}$ and 0.3-0.45 were adopted respectively. Figure 4 shows examples of resulting distributions for the soil parameters for models with $\mathrm{T}_{\mathrm{FB}}=1.0 \mathrm{sec}$.

In the next step, a degraded shear modulus, $G_{s e c}$, and soil material damping, $\xi_{e q}$ which are dependent on the predefined soil parameters were calculated. $G_{s e c}$ was calculated as:

$$
\mathrm{G}_{\mathrm{sec}}=\rho\left(\mathrm{V}_{\mathrm{s}}\right)_{\mathrm{sec}}^{2}
$$

whereas, $\xi_{e q}$ was assumed to linearly vary between $10-25 \%$ for the velocity degradation ratios of 0.7-0.15 respectively, and was calculated using the following expression: 


$$
\frac{25-\xi_{\mathrm{eq}}}{25-10}=\frac{\left(\mathrm{V}_{\mathrm{s}}\right)_{\mathrm{sec}} /\left(\mathrm{V}_{\mathrm{s}}\right)_{0}-0.15}{0.7-0.15}
$$

Figure $5 \mathrm{a}-5 \mathrm{c}$ show the resulting distributions of $\left(V_{s}\right)_{s e c}, G_{s e c}$, and $\xi_{e q}$, at $\mathrm{T}_{\mathrm{FB}}=1.0 \mathrm{sec}$.

\subsection{Selection of structural parameters}

Randomly varying structural parameters include: (i) structural effective height, $h_{\text {eff, }}$ (ii) foundation radius, $r$, and (iii) structural mass, $m_{s t r}$. Depending on these randomly generated parameters, the values for the structural lateral stiffness, $k_{s t r}$, and structural damping, $c_{s t r}$, were then calculated. To achieve realistic SFS models, the selection of the introduced structural parameters was constrained by commonly accepted relationship either for the superstructure or for the whole SFS model. The first parameter to be established was $h_{\text {eff. }}$ For each group of models with a specified $T_{F B}$ (17 groups with $\left.\mathrm{T}_{\mathrm{FB}}=0.2,0.3, \ldots, 1.8 \mathrm{sec}\right)$, a range of variation for $h_{\text {eff }}$ was defined based on: $(i)$ a typical period-height relationship adopted in NZS 1170.5 [33] that can be expressed as:

$$
0.085\left(\mathrm{~h}_{\text {eff }}\right)^{0.75} \leq \mathrm{T}_{\mathrm{FB}} \leq 0.19\left(\mathrm{~h}_{\text {eff }}\right)^{0.75}
$$

and (ii) the considered limitation on the height of the structure of 3-30 (m). It was assumed that $h_{\text {eff }}$ is uniformly distributed (equally likely to occur) in the above defined range. After defining $h_{\text {eff }}$ at each $T_{F B}$ for 1000 models, the building aspect ratio, $h_{\text {eff }} / r$, was used to calculate the foundation radius, $r$. It was assumed that the ratio $h_{e f f} / r$ for ordinary (residential/commercial) buildings is in the range between 1 and 4 and that $r$ is limited to be between 2 and $12 \mathrm{~m}$, representing structures having 1-3 bays with length of 4-8 m. For each predefined value of $h_{\text {eff }}$, a random value was picked for $r$ satisfying the above mentioned constraints. For each model, the foundation radius along with the selected soil parameters was used to calculate the coefficients of the soil-foundation 
element. To define a realistic structural mass, $m_{s t r}$, for the defined structural and soil parameters, the relative mass index $\bar{m}$ was used:

$$
\overline{\mathrm{m}}=\frac{\mathrm{m}_{\text {str }}}{\rho \mathrm{r}^{2} \mathrm{~h}_{\mathrm{eff}}}
$$

For ordinary structures, $\bar{m}$ varies between $0.4-0.6$ [4,28]. Thus, knowing previously defined values for $h_{e f f}, r$, and $\rho$, and considering a uniform distribution for $\bar{m}$ within the defined range, the value for the structural mass, $m_{s t r}$, was defined. Following this estimation of $m_{s t r}$, the initial structural stiffness, $\left(k_{s t r}\right)_{i}$ was calculated directly using:

$$
\left(\mathrm{k}_{\mathrm{str}}\right)_{\mathrm{i}}=\frac{4 \pi^{2}}{\mathrm{~T}_{\mathrm{FB}}^{2}} \mathrm{~m}_{\mathrm{str}}
$$

To determine the structural damping coefficient, $c_{s t r}$, a constant $5 \%$ equivalent viscous structural damping was employed, and $c_{s t r}$ was defined as:

$$
\mathrm{c}_{\mathrm{str}}=2(0.05) \sqrt{\left(\mathrm{k}_{\mathrm{str}}\right)_{\mathrm{i}} \mathrm{m}_{\mathrm{str}}}
$$

Figure $5 \mathrm{~d}$ illustrates the distribution of $m_{\text {str }}$ obtained for $\mathrm{T}_{\mathrm{FB}}=1.0 \mathrm{sec}$. It can be concluded from Equations 7 and 8, that the distributions of $\left(k_{s t r}\right)_{i}$ and $c_{s t r}$ will be similar to that of $m_{\text {str }}$.

To represent the nonlinear cyclic force-deflection behaviour of the superstructure, two models were used: (i) bilinear elastic-plastic (BLEP) and (ii) Takeda degrading stiffness (TKDS). In each model, the linear branch was considered to be equal to $\left(k_{s t r}\right)_{i}$ and the yield strength was defined assuming a displacement ductility of 6 at $2 \%$ drift. This ductility limit was selected in order to ensure nonlinear behaviour within the superstructure. For both models, the post-yielding stiffness factor $\alpha$ was considered to be 0.05 ( $5 \%$ of the linear branch), and parameters $\gamma=0.3$ and $\delta=0.2$ were selected for the TKDS model ( $\alpha, \gamma$ and $\delta$ are defined in Figure 2). 
Thus, given all the parameters of the model, the predominant period of the SFS system could be calculated as:

$$
\mathrm{T}_{\mathrm{SFS}}=\mathrm{T}_{\mathrm{FB}} \sqrt{1+\frac{\left(\mathrm{k}_{\mathrm{str}}\right)_{\mathrm{i}}}{\mathrm{k}_{0}}+\frac{\left(\mathrm{k}_{\mathrm{str}}\right)_{\mathrm{i}} \mathrm{h}_{\mathrm{eff}}^{2}}{\mathrm{k}_{\varphi}}}
$$

The relation between this calculated period $\left(\mathrm{T}_{\mathrm{SFS}}\right)$ and the period of the corresponding FB structure $\left(\mathrm{T}_{\mathrm{FB}}\right)$ for the generated models is shown in Figure 6. This graph illustrates the range of the uncertainty that accompanies the stochastic SFS models determined as above.

\subsection{Selected earthquake ground motions and scaling scheme}

To cover the aleatory uncertainties caused by record-to-record variability, all adopted SFS models were subjected to a large number of earthquake ground motions with different characteristics. An ensemble of 40 earthquake ground motions recorded on stiff/soft soil (soil type C, $\mathrm{V}_{\mathrm{s}}=180-360 \mathrm{~m} / \mathrm{sec}$, and $\mathrm{D}, \mathrm{V}_{\mathrm{s}}<180 \mathrm{~m} / \mathrm{sec}$ to a depth of $30 \mathrm{~m}$, based on USGS classification) was used in the analyses. All selected records are from earthquakes with magnitude of 6.5-7.5 and have source-to-site distance in the range of $15-40 \mathrm{~km}$.

These records were scaled to have peak ground acceleration (PGA) within the range of $0.3-0.8 \mathrm{~g}$, assuming that nonlinear behaviour of the superstructure would be induced from earthquakes of such intensity. The outcome of the adopted scaling scheme was to have 10 records with $0.3 \mathrm{~g} \leq \mathrm{PGA} \leq 0.4 \mathrm{~g}, 20$ records with $0.4 \mathrm{~g} \leq \mathrm{PGA} \leq 0.6 \mathrm{~g}$ and 10 records with $0.6 \mathrm{~g} \leq \mathrm{PGA} \leq 0.8 \mathrm{~g}$ (Figure 7), with all applied scaling factors in the range of 1.7-2.7. Normalized elastic acceleration response spectra (5\% damping) including the median spectrum of the selected ground motions are shown in Figure 8. 


\subsection{Presentation of structural behaviour}

The response of the superstructure due to SFSI effects were examined using two response parameters: (i) structural distortion, $u$, and (ii) structural total displacement, $u_{s t r}$ Structural distortion is the horizontal displacement of the structure relative to the foundation while structural total displacement is defined by the sum of the horizontal foundation displacement, structural lateral displacement due to foundation rocking, and structural distortion. Only the maximum values for $u$ and $u_{s t r}$ resulting from a given time-history analysis are examined herein. These values are presented in a normalized form as a ratio between the response of the SFS model and respective FB model computed for the same earthquake excitation. Hence, when $(i)$ structural distortion modification factor is greater than unity, $u_{S F S} / u_{F B}>1.0$, or (ii) structural total displacement modification factor is greater than unity, $\left(u_{s t r}\right)_{S F S} /\left(u_{s t r}\right)_{F B}>1.0$, the SFSI increases the structural response or has detrimental effects on the response

\subsection{Presentation of the probabilistic analysis outcomes}

To characterize the central tendency of the seismic response of the SFS system, the median value was selected as the statistical measure. The dispersion around that median value is presented in a box and whisker plot in which the box has lines at $25^{\text {th }}$ percentile (bottom line), median (middle line), and $75^{\text {th }}$ percentile (top line) values. Whiskers extend from each end of the box to the $5^{\text {th }}$ and $95^{\text {th }}$ percentiles respectively. Outliers are the data with values beyond those indicated by the whiskers. This presentation allows evaluating the SFSI effects at different levels of probability. 


\section{SFSI EFFECTS ON STRUCTURAL RESPONSE}

In the Monte Carlo simulation, the randomly selected but realistic models $(2 \times 3 \times 17000$ SFS and FB models), were subjected to 40 earthquake ground motions yielding 4.08 million analyses in total. The results from the analyses are presented in three sections: (i) the SFSI effects on structural linear and nonlinear response; (ii) the risk of having detrimental SFSI (DSFSI) effects on structural seismic response and the corresponding level of increase; (iii) the likelihood of DSFSI scenario as a function of key SFS system parameters.

\subsection{Quantification of SFSI effects on structural response}

Structural Distortion: Figure 9 displays the median and dispersion of structural distortion modification factor $\left(u_{S F S} / u_{F B}\right)$ for different groups of SFS models categorized in terms of $T_{F B}$. Note that at each specific $T_{F B}$, the resulting responses from 40,000 different analyses are presented (40 earthquakes and 1000 models). As shown in Figure 9, the median value of $u_{S F S} / u_{F B}$ is less than unity for all these structural models, indicating that, on average, SFSI reduces the structural response. However, the $75 \%$ line (top of the box) does show values greater than unity across all periods for the nonlinear analyses. In other words, for nearly $25 \%$ of all cases showing nonlinear behaviour, SFSI has detrimental effects and increases the structural response. In the extreme case, SFSI may increase the structural distortion up to 3 times.

It should be noted that the total dispersion around the median response is larger for the nonlinear structural systems as compared to that of linear systems. This result clearly shows that for $25 \%$ of all cases, the simplified approach using linear structures and ignoring SFSI effects would be unconservative. 
To investigate the effect of structural nonlinearity on the median response, Figure 10 compares the median structural distortion modification factors for the three structural models (BLEP, TKDS and linear). Clearly, the median reduction ratio in structural distortion due to SFSI effects is between 0.7-0.95 for linear cases and between 0.85-1.0 for nonlinear structural systems. This shows more explicitly that SFSI effects on structural distortion result in greater response for nonlinear than linear structural systems.

Structural Total Displacement: Figure 11 illustrates the median structural total displacement modification factor $\left(\left(u_{s t r}\right)_{S S F S}\left(u_{s t r}\right)_{F B}\right)$ for all three structural models. As clearly illustrated, considering foundation flexibility increases the total displacement for both nonlinear models across the entire range of periods considered. For linear structural systems, the foundation flexibility increases the total displacement of the structure only for very stiff structures $\left(\mathrm{T}_{\mathrm{FB}}<0.5 \mathrm{sec}\right)$.

A more detailed presentation of the response is given in Figure 12 indicating the dispersion as well as the level of the modification factor for the $75^{\text {th }}$ and $95^{\text {th }}$ percentiles. For $25 \%$ of the cases with nonlinear structural behaviour, the increase in the total displacement due to SFSI effects is greater than 1.1-1.35 depending on $\mathrm{T}_{\mathrm{FB}}$. In the extreme cases, this factor of increase may be as high as 15 . Figure 11 and 12 show that amplification effects of SFSI on the structural total displacement decrease with the flexibility of the structure.

\subsection{Evaluation of the risk for detrimental SFSI Effects}

To quantify the detrimental SFSI effects on the response of the superstructure, two main aspects should be considered: $(i)$ the probability to cause amplification in the response 
of the superstructure as compared to the response of a FB model; and (ii) the level of increase in the structural response due to SFSI.

Structural Distortion: Figure $13 \mathrm{a}$ presents the probability to increase structural distortion response due to SFSI effects (probability of the cases in which $u_{S F S} / u_{F B}>1.0$ ) across the range of all considered periods. The observed probability is between $10-30 \%$ for linear structural systems and between $30-60 \%$ for nonlinear structural systems. Clearly, this probability increases due to nonlinear effects in the structural response. It is also apparent that, the probability of having an increase in the response is higher for stiffer structures $\left(\mathrm{T}_{\mathrm{FB}}<0.5 \mathrm{sec}\right)$, indicating that stiff structures are more likely to exhibit detrimental SFSI effects in terms of structural distortion. Figure $13 \mathrm{~b}$ illustrates that the median percentage increase in the response due to SFSI is about $3-8 \%$. Figure $14 \mathrm{a}$ shows that the probability for a $10 \%$ or larger increase in the response of nonlinear models $\left(u_{S F S} / u_{F B}>1.1\right)$ is about $5-20 \%$, while there is $2-8 \%$ probability for a $25 \%$ or larger increase in the response $\left(u_{S F S} / u_{F B}>1.25\right)$. This figure also shows that the probability of a $10 \%$ increase in the structural distortion for linear models is similar to the probability of a $25 \%$ increase for nonlinear cases, which again emphasizes the more pronounced SFSI effects in nonlinear structures. In order to represent the risk of DSFSI effects on structural distortion in extreme cases, Figure $14 \mathrm{~b}$ shows the probability of the cases in which $u_{S F S} / u_{F B}>1.5$ along with the median values of the percentage increase in the response due to SFSI. This probability is less than $2 \%$ while the median percentage increase is about $50-70 \%$.

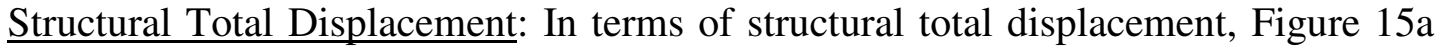
illustrates the probability of having an amplified structural total displacement response due to SFSI consideration (probability of the cases in which $\left.\left(u_{s t r}\right)_{S F S}\left(u_{S t r}\right)_{F B}>1.0\right)$. For 
linear structural systems, this probability is within the range of $40-80 \%$, and for nonlinear structures this ratio increases to $60-90 \%$. Similar to the observation for structural distortion, this probability also increases with structural stiffness. The median increase in the response is about $7-17 \%$ (Figure $15 \mathrm{~b}$ ). The probability for a $10 \%$ or higher increase in the total displacement of nonlinear models $\left(\left(u_{s t r}\right)_{S F S} /\left(u_{s t r}\right)_{F B}>1.1\right)$ due to SFSI effects is $25-50 \%$, while there is $10-30 \%$ likelihood that $\left(u_{s t r}\right)_{S F S} /\left(u_{s t r}\right)_{F B}>1.25$ as illustrated in Figure 16a. For extreme scenarios, the probability for a $50 \%$ or greater increase in the response, $\left(u_{s t r}\right)_{S F S} /\left(u_{s t r}\right)_{F B}>1.5$, is between $2-15 \%$ which is accompanied with a median percentage increase in response of about $60-80 \%$.

\subsection{Correlation between detrimental scenarios and key system parameters}

To investigate the correlation between key system parameters and scenarios showing detrimental soil-foundation-structure interaction (DSFSI) effects, the conditional probability of having a DSFSI scenario given a considered system parameter, denoted by $\operatorname{Pr}\left[\mathrm{DSFSIIX}=\mathrm{x}_{\mathrm{i}}\right]$, was evaluated as:

$$
\operatorname{Pr}\left[\text { DSFSI } \mid \mathrm{X}=\mathrm{x}_{\mathrm{i}}\right]=\frac{\operatorname{Pr}\left[\mathrm{X}=\mathrm{x}_{\mathrm{i}} \mid \mathrm{DSFSI}\right] \operatorname{Pr}[\mathrm{DSFSI}]}{\operatorname{Pr}\left[\mathrm{X}=\mathrm{x}_{\mathrm{i}}\right]}=\frac{\mathrm{N}_{1}}{\mathrm{M}_{1}}
$$

where $N_{1}$ is the number of models with DSFSI effect and $\mathrm{X}=\mathrm{x}_{\mathrm{i}}$, and $\mathrm{M}_{1}$ is the number of all models with $\mathrm{X}=\mathrm{x}_{\mathrm{i}}$. In addition to the calculated conditional probability, the median value of the percentage increase in the response was also evaluated. Three system parameters were considered in this investigation, $\tilde{h}, \tilde{m}$ and $\tilde{\omega}$ representing the structural aspect ratio, the structure-to-soil mass ratio and the structure-to-soil stiffness ratio respectively. 
Figure $17 \mathrm{a}$ and $17 \mathrm{~b}$ illustrate the probability of DSFSI due to variation in $\tilde{h}$ for $u_{S F S} / u_{F B}>1.0$ and $\left(u_{s t r}\right)_{S F S} /\left(u_{s t r}\right)_{F B}>1.0$ scenarios respectively. With regard to $u_{S F S} / u_{F B}>1.0$, an increase in $\tilde{h}$ causes a slight decrease in the probability for detrimental effects. However, for $\left(u_{s t r}\right)_{S F S} /\left(u_{s t r}\right)_{F B}>1.0$, the probability of DSFSI decreases up to $\tilde{h}=2$ and then remains constant afterwards. As shown in these figures, the median value of increase in the response is about $5 \%$ for structural distortion and in the range between $10 \%$ and $15 \%$ for the total displacement respectively. As discussed in Section 4.1, the probability for detrimental effects is greater for nonlinear behaviour of the superstructure. Similar trends and values to those observed for $\tilde{h}$ in Figure 17 were also obtained for the mass ratio $\tilde{m}$.

As shown in Figure 18a, the probability of DSFSI is highest at low values of $\tilde{\omega}$ and decreases sharply with an increase in $\tilde{\omega}$, when the structural distortion is used as a measure for the structural response. For linear structural systems having $\tilde{\omega} \geq 2.5$, the risk of having DSFSI scenario can be practically ignored. This threshold rises to $\tilde{\omega} \geq 4.5$ for nonlinear structural systems. On the other hand, when the total displacement is considered and cases of $\left(u_{s t r}\right)_{S F S} /\left(u_{s t r}\right)_{F B}>1.0$ are to be identified, the probability of DSFSI does not show any significant trend or relation with $\widetilde{\omega}$. It is interesting to note that the level of median increase in the response due to SFSI effects shows more complex relation with $\tilde{\omega}$, and generally increases with the value of $\tilde{\omega}$. This trend is particularly significant for the total displacement, $\left(u_{s t r}\right)_{S F S} /\left(u_{s t r}\right)_{F B}>1.0$, where the increase in the response can be up to $75 \%$, at high values of $\tilde{\omega}$. Unlike the parameters $\tilde{h}$ and $\tilde{m}$ which showed weak or no correlation with the SFSI effects, the probability of detrimental SFSI scenarios (DSFSI) is strongly correlated with the stiffness ratio $\tilde{\omega}$. 


\section{CONCLUSIONS}

The effects of soil-shallow foundation-structure interaction (SFSI) on the seismic response of structures have been investigated using a robust Monte-Carlo simulation. A large number of models with varying soil, foundation and structural properties were used to systematically examine the response of realistic SFS systems when subjected to 40 earthquake excitations with different ground motion characteristics. Based on statistical analysis of the results from 4.08 million analyses, the following conclusions can be made:

1- In median terms, SFSI effects on the seismic response of structures exhibiting nonlinear behaviour are relatively small. The median structural distortion of SFS systems is about the same (or 5-10\% smaller) with that of a respective fixed-base structure while the total displacement increases due to SFSI effects for $2-10 \%$.

2- There is $5-15 \%$ likelihood for a $10 \%$ or greater increase in the structural distortion (relative to the fixed-base response) and 2-7\% likelihood for increase in this response of over $25 \%$. The probability for an in crease in the structural distortion due to SFSI of over $50 \%$ is less than $2 \%$.

3- There is $30-50 \%$ probability for an increase in the total structural displacement of over $10 \%$ due to SFSI , $10-30 \%$ probability for amplification of greater than $25 \%$ and $2-15 \%$ for an increase of over $50 \%$ in this response.

4- The amplification of structural displacements due to SFSI effects is more significant for structures exhibiting nonlinear behaviour. The responses obtained for the two nonlinear models (BLEP and TKDS) were generally similar. 
5- The structural aspect ratio $(\tilde{h})$ and the mass ratio $(\tilde{m})$ show very similar and relatively small effects on the response of SFS systems, though the trends of their effects are well defined.

6- The stiffness ratio $\tilde{\omega}$ shows strong correlation with the SFSI effects. The probability for an increase in the structural distortion due to SFSI effects is the highest for very low values of $\tilde{\omega}$; this probability sharply reduces with $\tilde{\omega}$ and asymptotically approaches zero for $\tilde{\omega}>4.5$. Conversely, the median increase in the total displacement in the structure steadily increases with $\tilde{\omega}$ and reaches values of over $60 \%$ median increase for $\tilde{\omega}>4.5$.

\section{REFERENCES}

1. Jennings PC, Beilak J. Dynamics of building-soil interaction. Bulletin of the Seismological Society of America 1973; 63(1):9-48.

2. Veletsos AS, Meek JW. Dynamic behaviour of building-foundation systems. Earthquake Engineering and Structural Dynamics 1974; 3:121-38.

3. Veletsos AS, Nair VVD. Seismic interaction of structures on hysteresis foundations. Journal of the Structural Division (ASCE) 1975; 101:109-129.

4. Stewart JP, et al. Revisions to soil-structure interaction procedures in NEHRP design provisions. Earthquake Spectra 2003; 19(3): 677-96.

5. Applied Technology Council. Tentative Provisions for the Development of Seismic Regulations for Buildings; ATC-3-06: California, 1984.

6. FEMA 450. NEHRP Recommended Provisions and Commentary for Seismic Regulations for New Buildings and Other Structures. BSSC: Washington, 2004.

7. FEMA 440. Recommended Improvements of Nonlinear Static Seismic Analysis Procedures. Applied Technology Council: California, 2005.

8. Gazetas G, Mylonakis G. Seismic soil-structure interaction: new evidence and emerging issues. Geotechnical Earthquake Engineering and Soil Dynamics 3: proceedings of speciality conference. ASCE 1998; 1119-74.

9. Mylonakis G, Gazetas G. Seismic soil-structure interaction: beneficial or detrimental. Journal of Earthquake Engineering 2000; 4(3): 227-301.

10. Dutta SC, Bhattacharya K, Roy R. Response of low-rise buildings under seismic ground excitation incorporating soil-structure interaction. Soil Dynamics and Earthquake Engineering 2004; 24:893914.

11. Moghaddasi K. M, Cubrinovski M, Pampanin S, Carr A, Chase JG. Monte Carlo Simulation of SSI Effects Using Simple Rheological Soil Model. 2009 NZSEE Conference. Christchurch, New Zealand: 3-5 April 2009.

12. Ciampoli M, Pinto PE. Effects of soil-structure interaction on inelastic seismic response of bridge piers. Journal of Structural Engineering 1995; 121(5):806-814.

13. Veletsos AS, Vebric B. Dynamics of elastic and yielding structure-foundation systems. Proceedings of the $5^{\text {th }}$ World Conference on Earthquake Engineering. Rome, 1974. 
14. Gazetas G, Mylonakis G. Soil-structure interaction effects on elastic and inelastic structures. Proceedings of the Fourth International Conference on Recent Advances in Geotechnical Earthquake Engineering and Soil Dynamics and Symposium. San Diego, California, 2001.

15. Miranda E, Bertero V. Evaluation of strength reduction factors of earthquake-resistant design. Earthquake Spectra 1994; 10(2): 357-379.

16. Zahng J, Tang Y. Evaluating soil-structure interaction effects using dimensional analysis. The $14^{\text {th }}$ World Conference on Earthquake Engineering. Beijing, China, 2008.

17. Aviles J, Perez-Rocha LE. Soil-structure interaction in yielding systems. Earthquake Engineering and Structural Dynamics 2003; 32: 1749-1771.

18. Rodriguez M, Montes R. Seismic response and damage analysis of buildings supported on flexible soils. Earthquake Engineering and Structural Dynamics 2000; 29: 647-665.

19. Duncan JM. Factors of safety and reliability in geotechnical engineering. Journal of Geotechnical and Geoenvironmental Engineering, ASCE 2000; 126(4): 307-314.

20. Breysse D, Niandou H, Elachachi S, Houy L. A generic approach to soil-structure interaction considering the effects of soil heterogeneity. Geotechnique 2004; 54(2): 143-150.

21. Jin S, Lutes LD, Sarkani S. Response variability for a structure with soil-structure interactions and uncertain soil properties. Probabilistic Engineering Mechanics 2000; 15: 175-183.

22. Lutes LD, Sarkani S, Jin S. Response variability of an SSI system with uncertain structural and soil properties. Engineering Structures 2000; 22:605-620.

23. Moghaddasi K. M, Cubrinovski M, Pampanin S, Carr A, Chase JG. A robust probabilistic evaluation of soil-foundation-structure interaction effects on structural response. International Workshop on Soil-Foundation-Structure Interaction. University of Auckland, New Zealand: 26-27 November 2009.

24. Raychowdhury P. Effect of soil parameter uncertainty on seismic demand of low-rise steel buildings on dense silty sand. Soil Dynamics and Earthquake Engineering 2009; 29:1367-1378.

25. Wolf JP. Foundation Vibration Analysis Using Simple Physical Model. Englewood Cliffs, NJ: Prentice-Hall, 1994.

26. Seed HB, Idriss IM. Soil moduli and damping factors for dynamic response analysis. Report EERC 70-10. Earthquake Engineering Research Centre, 1970.

27. Beilak J. Dynamic response of nonlinear building foundation systems. Earthquake Engineering and Structural Dynamics 1978; 7:17-30.

28. Nakhaei M, Ghanad MA. The Effect of Soil-Structure Interaction on Damage Index of Building. Engineering Structures 2008; 30:1491-99.

29. Seed HB, Idriss IM. Soil moduli and damping factors for dynamic response analysis. Report EERC 70-10. Earthquake Engineering Research Centre, 1970.

30. NZS 1170.5: Structural Design Actions. Part 5: Earthquake Actions. New Zealand; 2004.

31. Fishman, G. S. Monte Carlo: Concepts, Algorithms, and Applications. New York, Springer-Verlag; 1995.

32. Carr AJ. Ruaumoko, Nonlinear FEM Computer Program, Department of Civil Engineering, University of Canterbury, 2009.

33. Vucetic M, Dobry R. Effect of Soil Plasticity on Cyclic Response. Journal of Geotechnical Engineering 1991; 117(1):89-107. 


\section{APPENDIX}

Table A. 1. Ground motions recorded on soil type C/D (USGS categorization) used as input motions in the analyses

\begin{tabular}{|c|c|c|c|c|c|c|c|c|c|}
\hline \multirow{2}{*}{ EQ } & \multirow{2}{*}{ Event } & \multirow{2}{*}{ Year } & \multirow{2}{*}{ Station } & R-Distance & \multirow{2}{*}{ Soil Type } & \multirow{2}{*}{$\mathbf{M}$} & \multirow{2}{*}{$\frac{\text { PGA }}{(\mathrm{g})}$} & \multirow{2}{*}{$\frac{\text { PGV }}{(\mathrm{cm} / \mathrm{s})}$} & \multirow{2}{*}{$\frac{\text { PGD }}{(\mathrm{cm})}$} \\
\hline & & & & $(\mathbf{k m})$ & & & & & \\
\hline EQ1 & \multirow{5}{*}{ Chi-Chi, Taiwan } & \multirow{5}{*}{1999} & CHY010/E & 25.4 & $\mathrm{C}$ & \multirow{5}{*}{7.6} & 0.23 & 21.9 & 11.1 \\
\hline $\mathrm{EQ} 2$ & & & $\mathrm{CHY} 034 / \mathrm{N}$ & 20.2 & $\mathrm{C}$ & & 0.31 & 48.5 & 16.5 \\
\hline EQ3 & & & CHY035/W & 18.2 & $\mathrm{C}$ & & 0.25 & 45.6 & 12.0 \\
\hline EQ4 & & & CHY036/W & 20.4 & $\mathrm{C}$ & & 0.29 & 38.9 & 21.2 \\
\hline EQ5 & & & NST/N & 37.0 & $\mathrm{C}$ & & 0.39 & 26.9 & 16.1 \\
\hline EQ6 & Kocaeli, Turkey & 1999 & Iznik/IZN090 & 31.8 & $\mathrm{C}$ & 7.4 & 0.14 & 28.8 & 17.4 \\
\hline EQ7 & Landers & 1992 & 22074 Yermo Fire Station/YER270 & 24.9 & $\mathrm{C}$ & 7.3 & 0.25 & 51.5 & 43.8 \\
\hline EQ8 & \multirow{8}{*}{ Loma Prieta } & \multirow{8}{*}{1989} & 57066 Agnews State Hospital/AGW000 & 28.2 & $\mathrm{C}$ & \multirow{8}{*}{6.9} & 0.17 & 26.0 & 12.6 \\
\hline EQ9 & & & 57191 Halls Valley/HVR000 & 31.6 & $\mathrm{C}$ & & 0.13 & 15.4 & 3.3 \\
\hline EQ10 & & & 1028 Hollister City Hall/HCH090 & 28.2 & $\mathrm{C}$ & & 0.25 & 38.5 & 17.8 \\
\hline EQ11 & & & 57382 Gilroy Array \#4/G04000 & 16.1 & $\mathrm{C}$ & & 0.42 & 38.8 & 7.1 \\
\hline EQ12 & & & 57425 Gilroy Array \#7/GMR090 & 24.2 & $\mathrm{C}$ & & 0.32 & 16.6 & 3.3 \\
\hline EQ13 & & & 1601 Palo Alto - SLAC Lab/SLC360 & 36.3 & $\mathrm{C}$ & & 0.28 & 29.3 & 9.7 \\
\hline EQ14 & & & 47179 Salinas - John \& Work/SJW250 & 32.6 & $\mathrm{C}$ & & 0.11 & 15.7 & 7.9 \\
\hline EQ15 & & & 1695 Sunnyvale - Colton Ave/SVL360 & 28.8 & $\mathrm{C}$ & & 0.21 & 36.0 & 16.9 \\
\hline EQ16 & \multirow{18}{*}{ Northridge } & \multirow{17}{*}{1994} & 25282 Camarillo/CMR180 & 36.5 & $\mathrm{C}$ & \multirow{17}{*}{6.7} & 0.13 & 10.9 & 3.5 \\
\hline EQ17 & & & 90053 Canoga Park - Topanga Can/CNP196 & 15.8 & $\mathrm{C}$ & & 0.42 & 60.8 & 20.2 \\
\hline EQ18 & & & 24575 Elizabeth Lake/ELI090 & 37.2 & $\mathrm{C}$ & & 0.16 & 7.3 & 2.7 \\
\hline EQ19 & & & 90063 Glendale - Las Palmas/GLP177 & 25.4 & $\mathrm{C}$ & & 0.36 & 12.3 & 1.9 \\
\hline EQ20 & & & 90054 LA - Centinela St/CEN155 & 30.9 & $\mathrm{C}$ & & 0.47 & 19.3 & 3.5 \\
\hline EQ21 & & & 90060 La Crescenta - New York/NYA090 & 22.3 & $\mathrm{C}$ & & 0.18 & 12.5 & 1.1 \\
\hline EQ22 & & & 90025 LA - E Vernon Ave/VER180 & 39.3 & $\mathrm{C}$ & & 0.15 & 10.1 & 1.8 \\
\hline EQ23 & & & 90034 LA - Fletcher Dr/FLE234 & 29.5 & $\mathrm{C}$ & & 0.24 & 26.2 & 3.6 \\
\hline EQ24 & & & 24303 LA - Hollywood Stor FF/HOL360 & 25.5 & $\mathrm{C}$ & & 0.36 & 27.5 & 3.0 \\
\hline EQ25 & & & 90016 LA - N Faring Rd/FAR000 & 23.9 & $\mathrm{C}$ & & 0.27 & 15.8 & 3.3 \\
\hline EQ26 & & & 24612 LA - Pico \& Sentous/PIC180 & 32.7 & $\mathrm{C}$ & & 0.19 & 14.3 & 2.4 \\
\hline EQ27 & & & 90022 LA - S Grand Ave/GR2090 & 36.9 & $\mathrm{C}$ & & 0.29 & 17.9 & 2.4 \\
\hline EQ28 & & & 90096 LA - S. Vermont Ave/VRM000 & 34.7 & $\mathrm{C}$ & & 0.16 & 10.7 & 1.8 \\
\hline EQ29 & & & 90091 LA - Saturn St/STN020 & 30.0 & $\mathrm{C}$ & & 0.47 & 34.6 & 6.6 \\
\hline EQ30 & & & 24055 Leona Valley \#5 - Ritter/LV5000 & 38.3 & $\mathrm{C}$ & & 0.15 & 14.9 & 2.4 \\
\hline EQ31 & & & 24309 Leona Valley \#6/LV6090 & 38.5 & $\mathrm{C}$ & & 0.18 & 14.4 & 2.1 \\
\hline EQ32 & & & 90095 Pasadena - N Sierra Madre/SMV180 & 39.2 & $\mathrm{C}$ & & 0.25 & 12.3 & 1.1 \\
\hline EQ33 & & 1987 & 5060 Brawley/B-BRA225 & 18.2 & $\mathrm{C}$ & 6.7 & 0.16 & 13.9 & 5.4 \\
\hline
\end{tabular}




\begin{tabular}{|c|c|c|c|c|c|c|c|c|c|}
\hline EQ34 & & & 5061 Calipatria Fire Station/B-CAL315 & 28.3 & $\mathrm{C}$ & & 0.25 & 14.6 & 3.1 \\
\hline EQ35 & & & 5052 Plaster City/B-PLS135 & 21.0 & $\mathrm{C}$ & & 0.19 & 20.6 & 5.4 \\
\hline EQ36 & Chi_Chi Taiwan & 1999 & CHY041/W & 26.0 & $\mathrm{D}$ & 76 & 0.30 & 20.4 & 8.6 \\
\hline EQ37 & Cill-cili, Ialwail & 1779 & TCU040/W & 21.0 & $\mathrm{D}$ & 1.0 & 0.15 & 50.9 & 57.4 \\
\hline EQ38 & Kobe & 1995 & 0 Kakogawa/KAK090 & 26.4 & $\mathrm{D}$ & 69 & 0.35 & 27.6 & 9.6 \\
\hline EQ39 & & & 0 Shin-Osaka/SHI000 & 15.5 & $\mathrm{D}$ & & 0.24 & 37.8 & 8.5 \\
\hline EQ40 & Superstition Hills (B) & 1987 & 5062 Salton Sea Wildlife Refuge/B-WLF315 & 27.1 & $\mathrm{D}$ & 6.7 & 0.17 & 18.3 & 4.3 \\
\hline
\end{tabular}




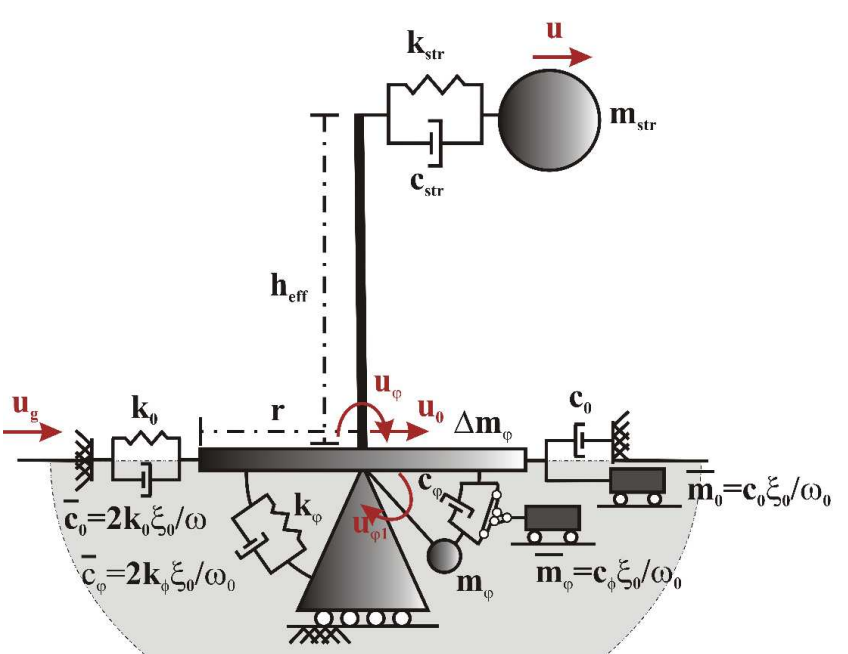

Equivalent Linear Half-Space

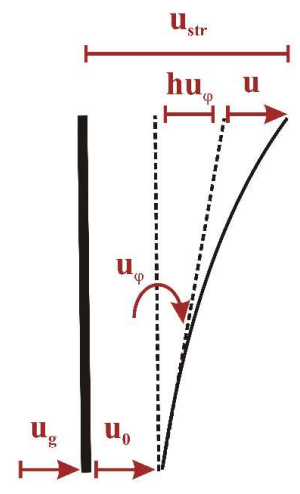

Structural Deformation

Figure 1. Coupled dynamic soil-shallow foundation-structure model for horizontal and rocking motions 

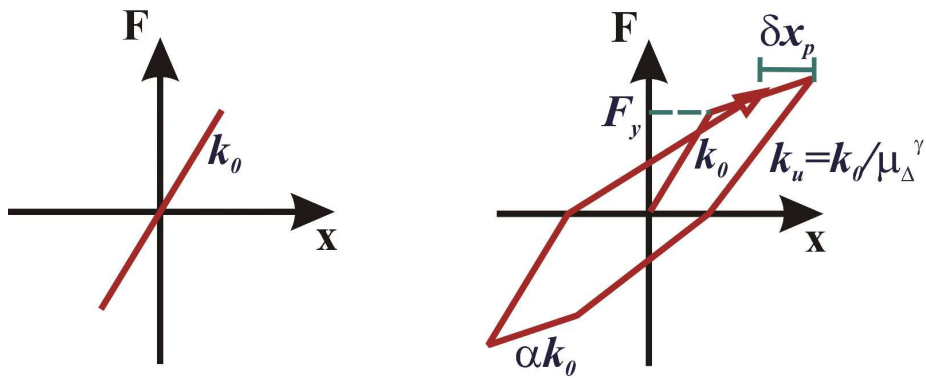

Linear Takeda Degrading Stiffness Bilinear Elasto-Plastic

Figure 2. Hysteresis models representing structural nonlinear response 


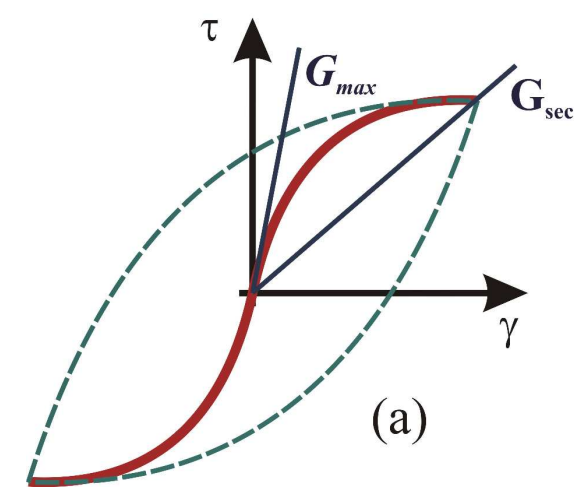

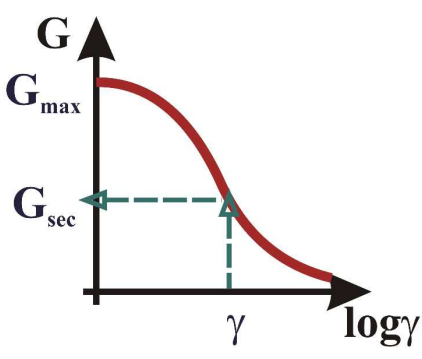

(b)

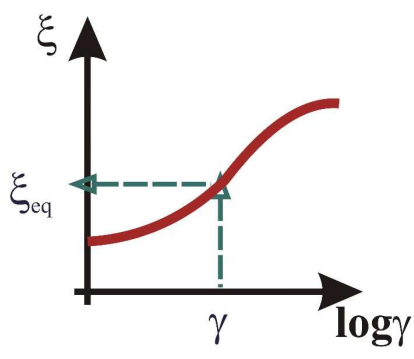

(c)

Figure 3. Equivalent linear idealization of non-linear soil behaviour: (a) shear stressstrain behaviour, (b) secant modulus vs. shear strain and (c) equivalent damping vs. shear strain 

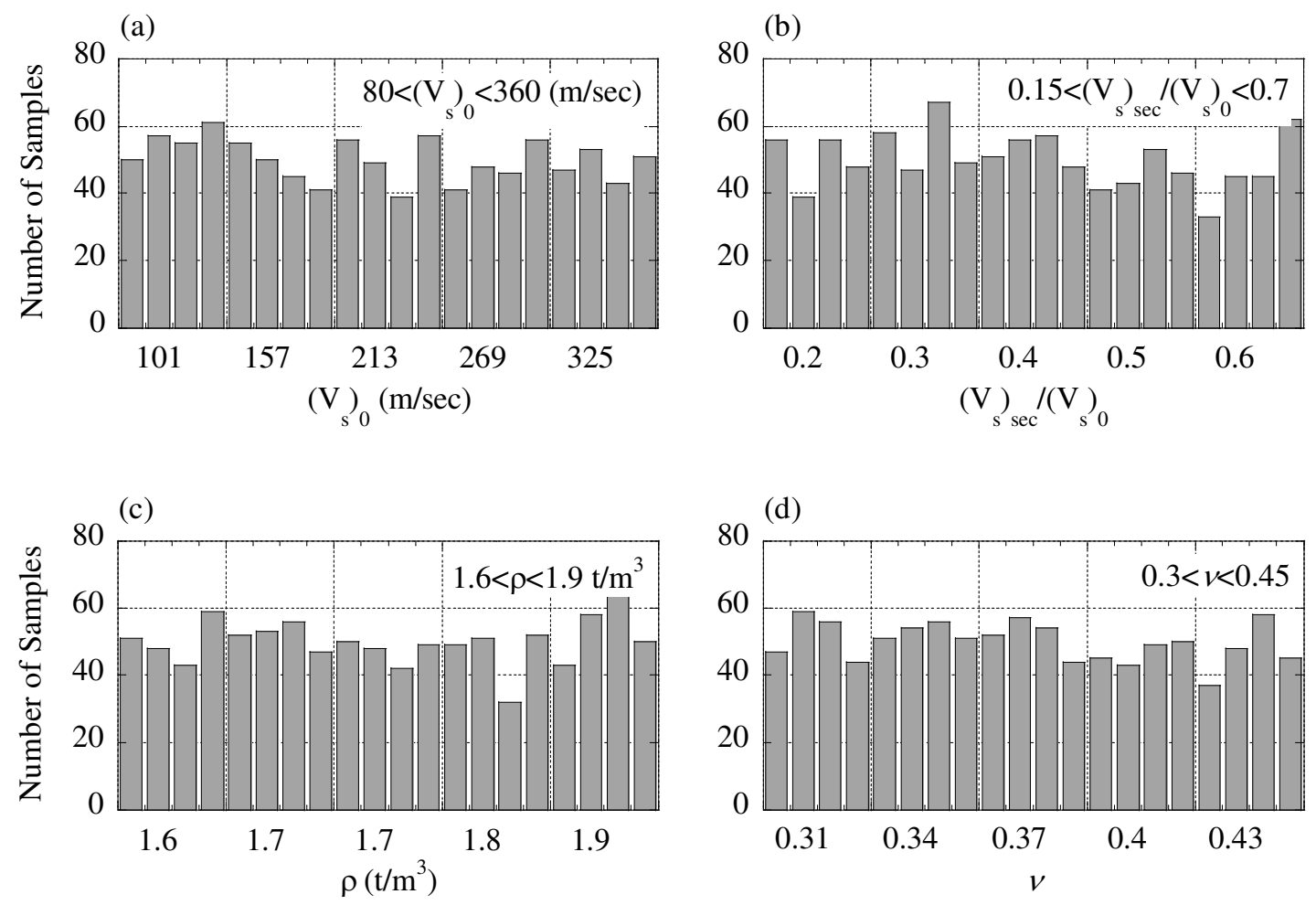

Figure 4. Distribution of: (a) initial shear wave velocity, (b) shear wave velocity degradation ratio, (c) soil mass density and (d) Poisson's ratio for $\mathrm{T}_{\mathrm{FB}}=1.0 \mathrm{sec}$ 
(a)

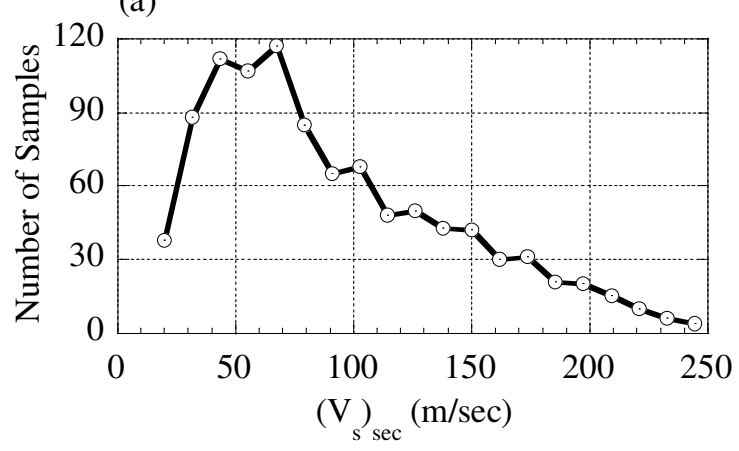

(c)

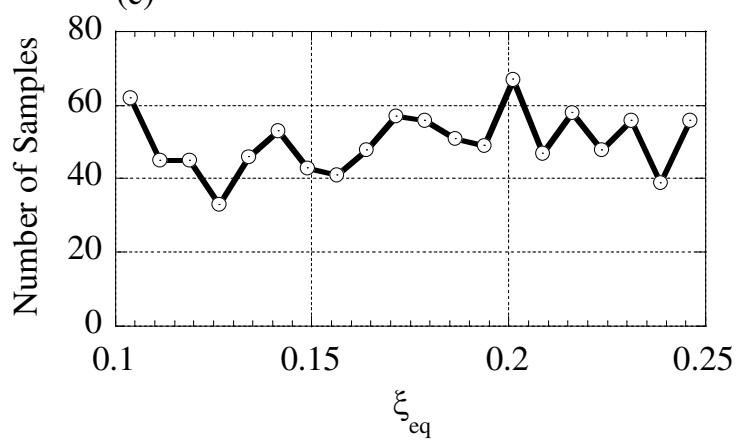

(b)

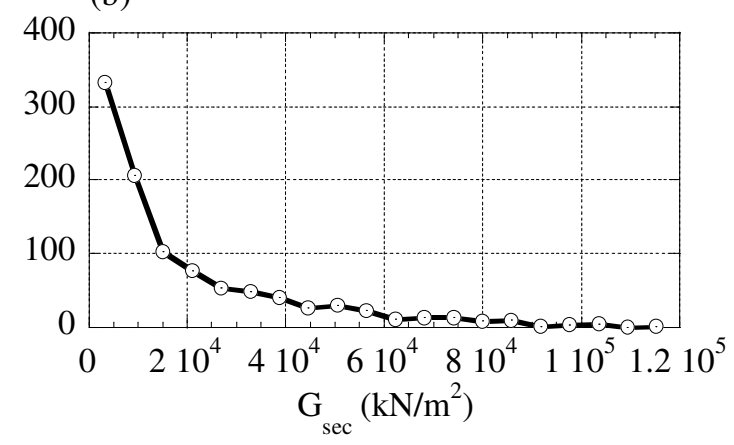

(d)

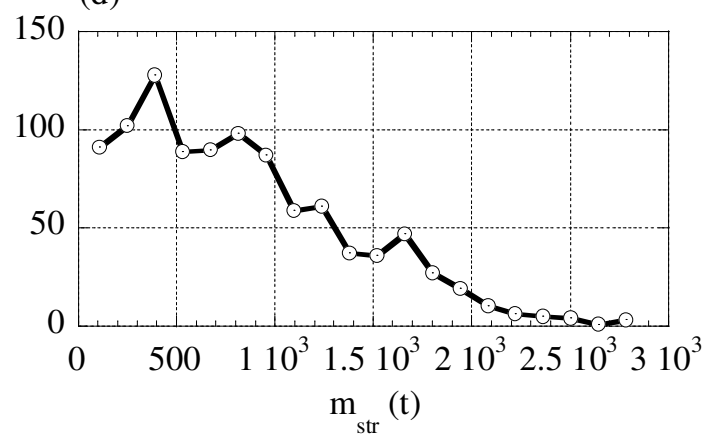

Figure 5. Distribution of: (a) degraded shear wave velocity, (b) degraded shear modulus (c) soil material damping and (d) structural mass for $\mathrm{T}_{\mathrm{FB}}=1.0 \mathrm{sec}$ 


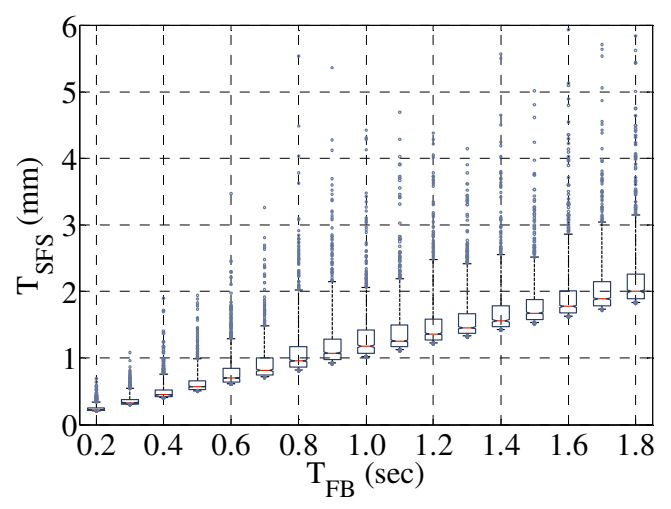

Figure 6. Presenting the period shift due to foundation flexibility 


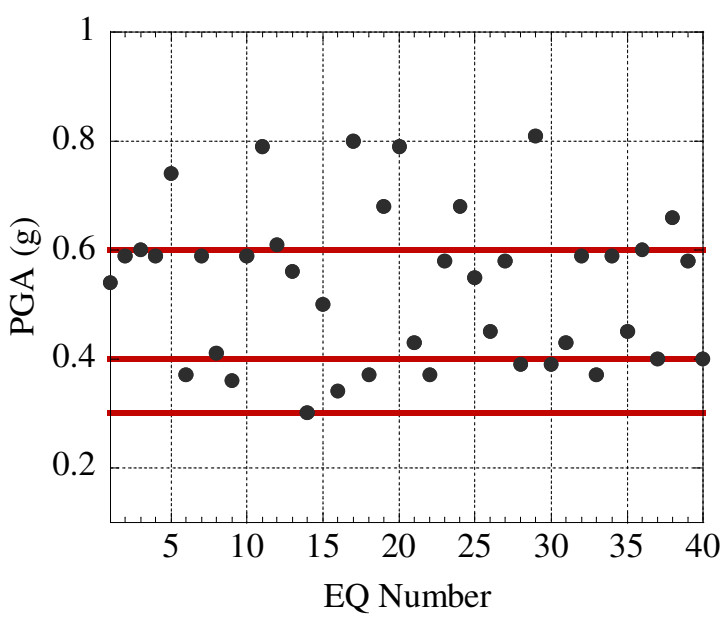

Figure 7. PGA distribution of the scaled records 


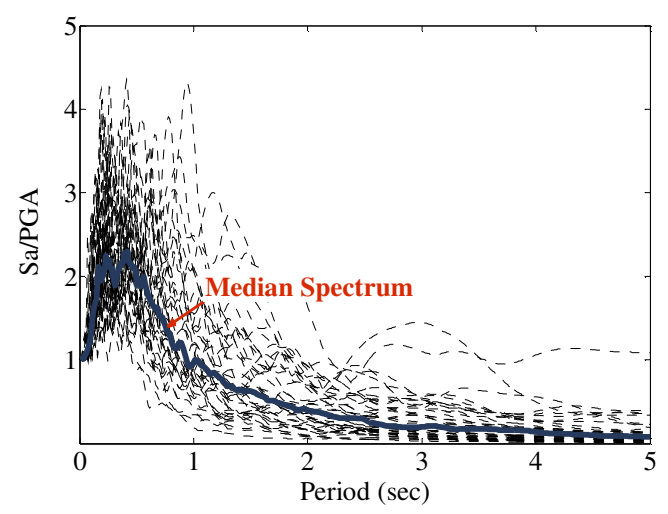

Figure 8. Normalized elastic acceleration response spectra (5\% elastic damping) of the selected earthquake ground motions to $\mathrm{PGA}=1.0 \mathrm{~g}$ 

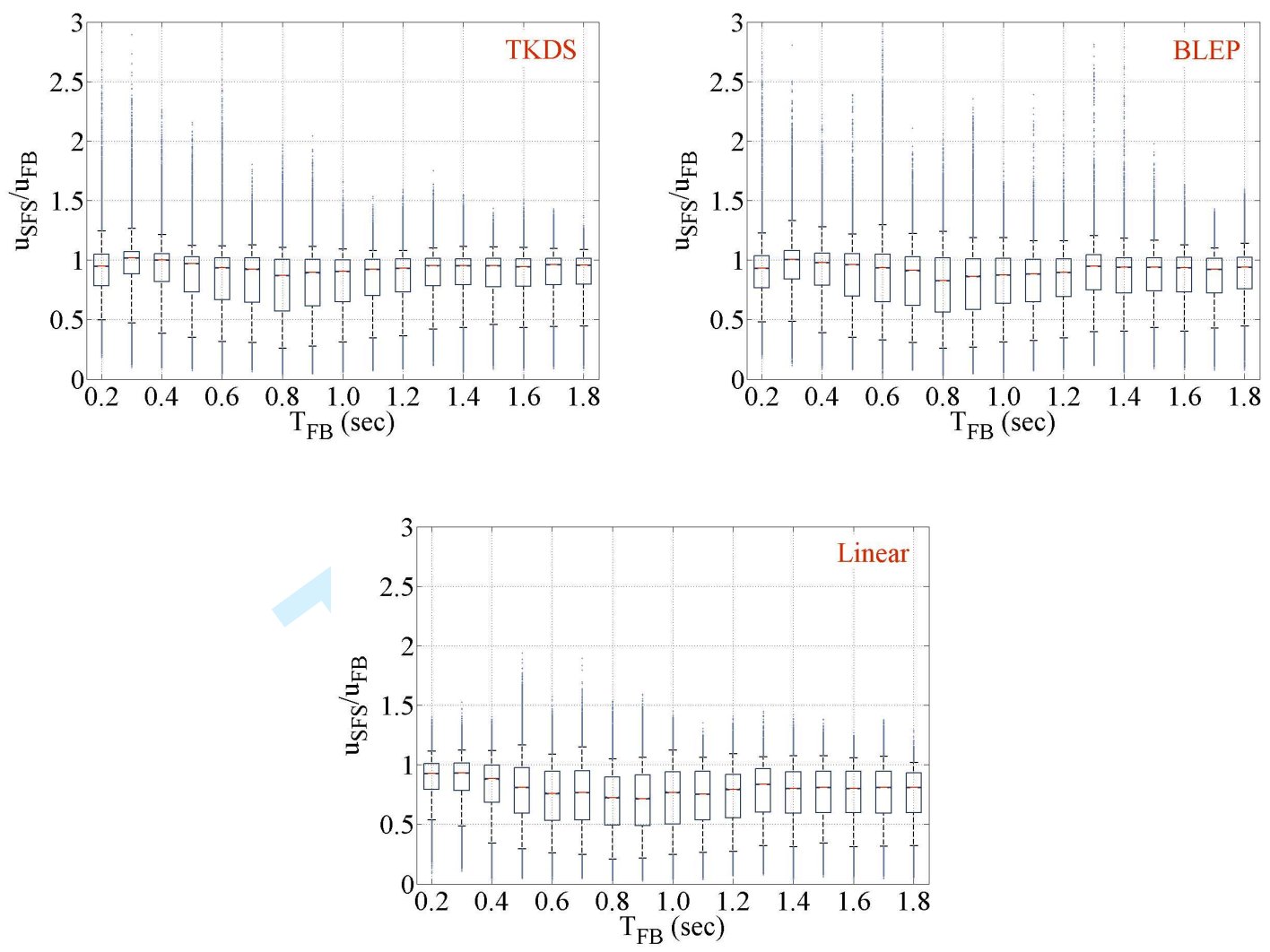

Figure 9. Structural distortion modification spectrum (IQR) for: Linear, TKDS and BLEP structural systems 


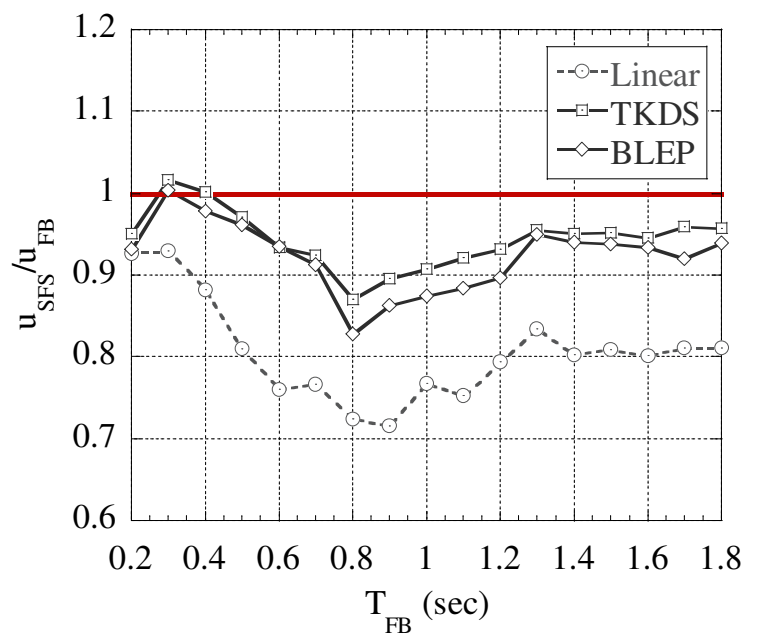

Figure 10. Median structural distortion modification spectrum 


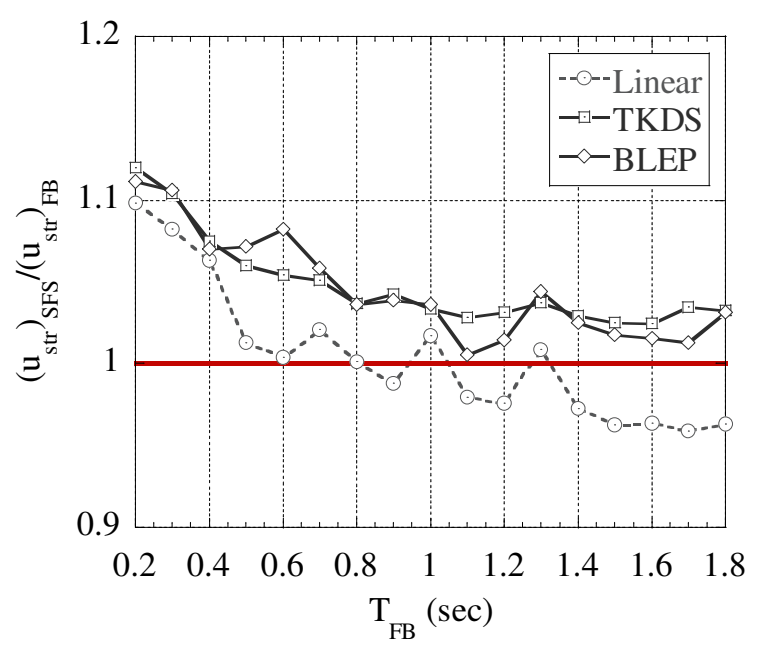

Figure 11. Median structural total displacement modification spectrum 

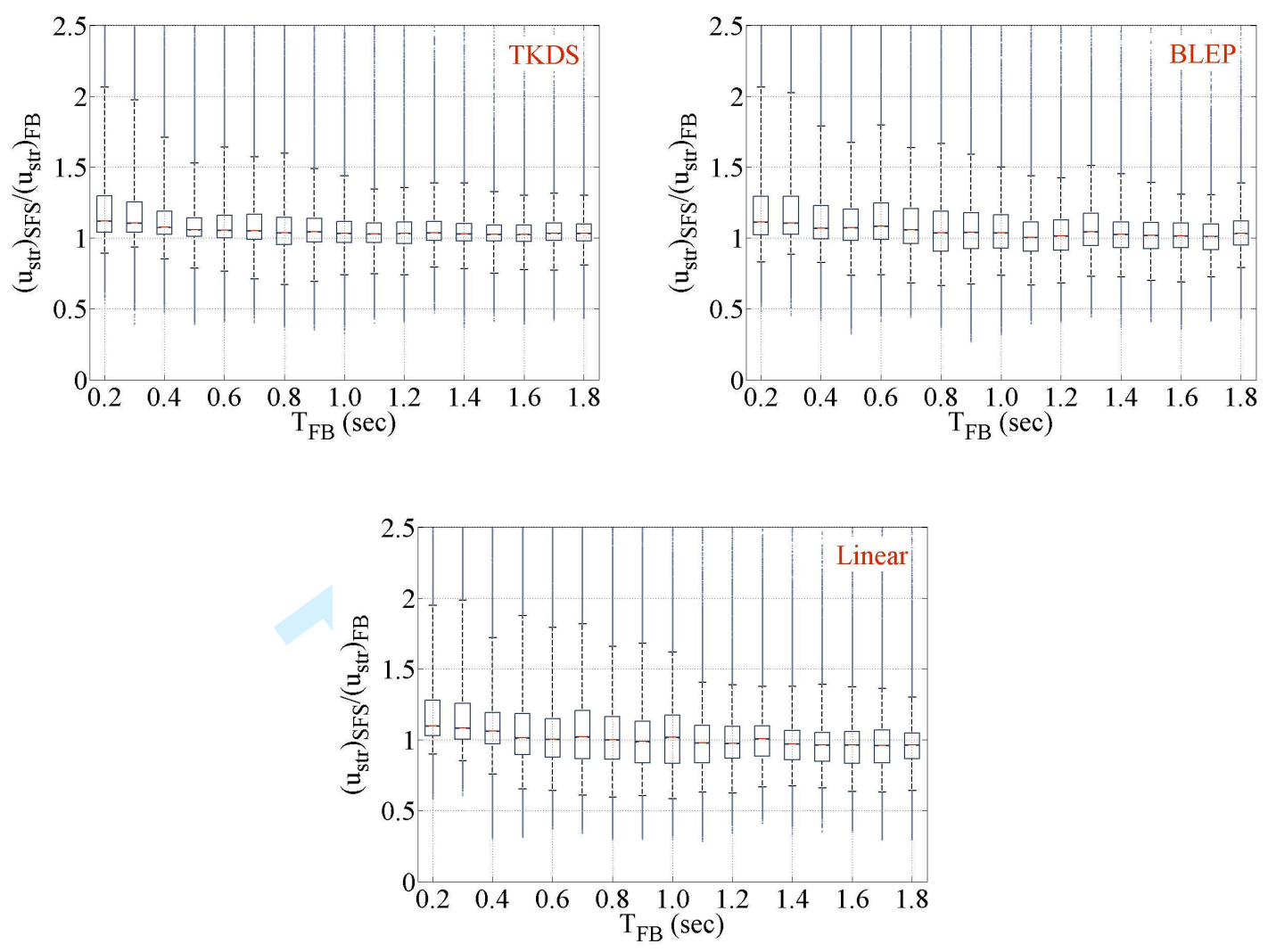

Figure 12. Structural total displacement modification spectrum (IQR) for: Linear, TKDS and BLEP structural systems 
(a)

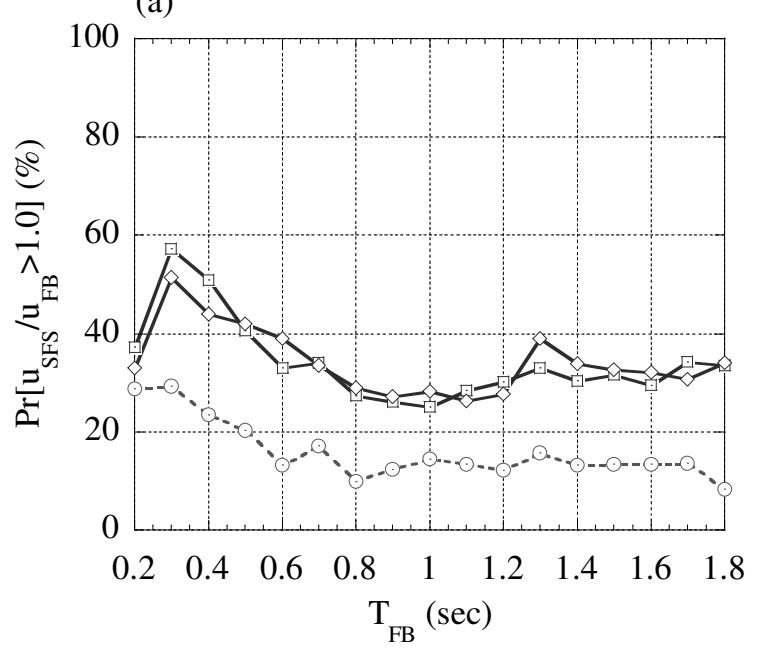

(b)

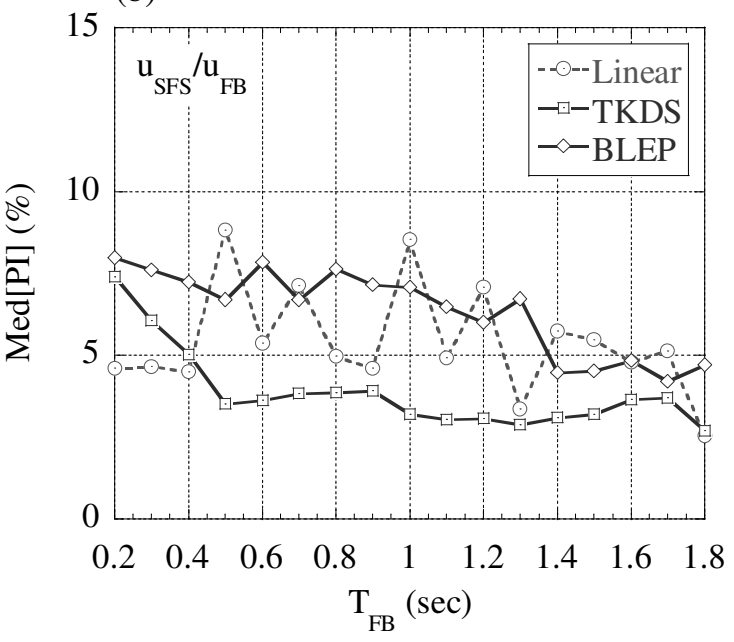

Figure 13. Structural distortion stochastic amplification spectrum: (a) probability of amplification, (b) median of percentage increase 
(a)

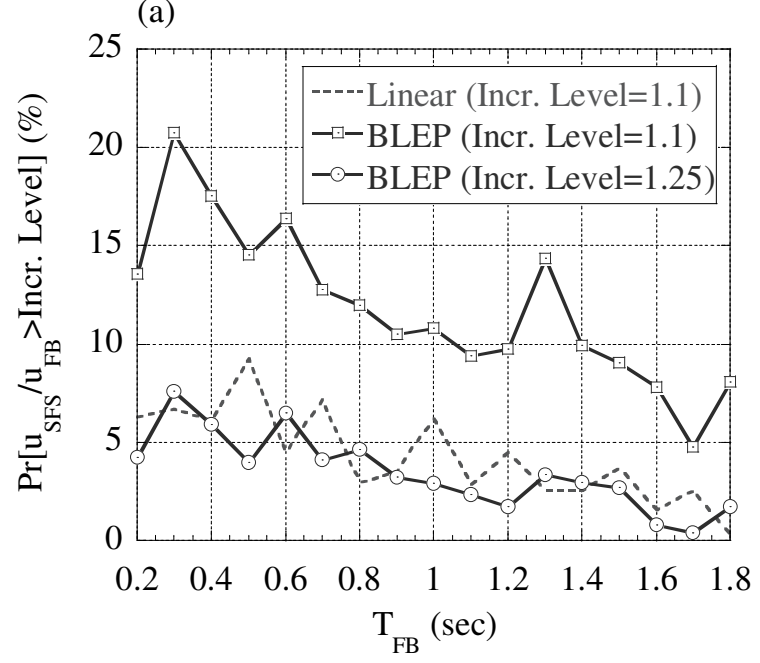

(b)

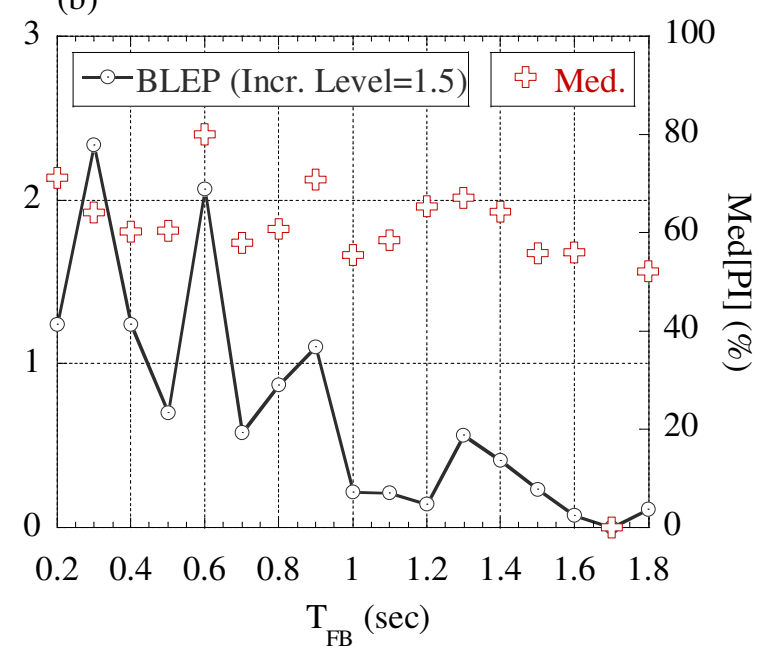

Figure 14. Structural distortion stochastic amplification spectrum: (a) for $10 \%$ and $25 \%$ of increase, (b) for $50 \%$ of increase in structural response 

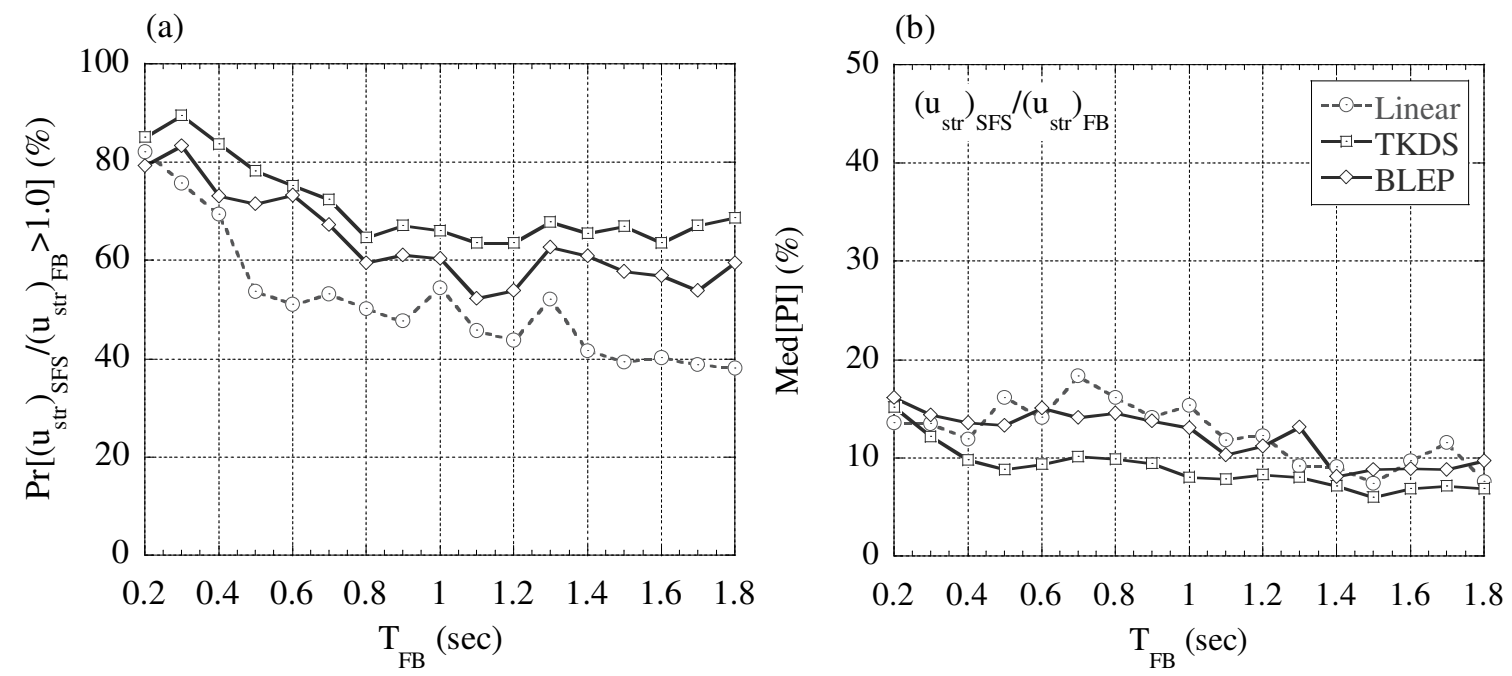

Figure 15. Structural total displacement stochastic amplification spectrum: (a) probability of amplification, (b) median of percentage increase 
(a)

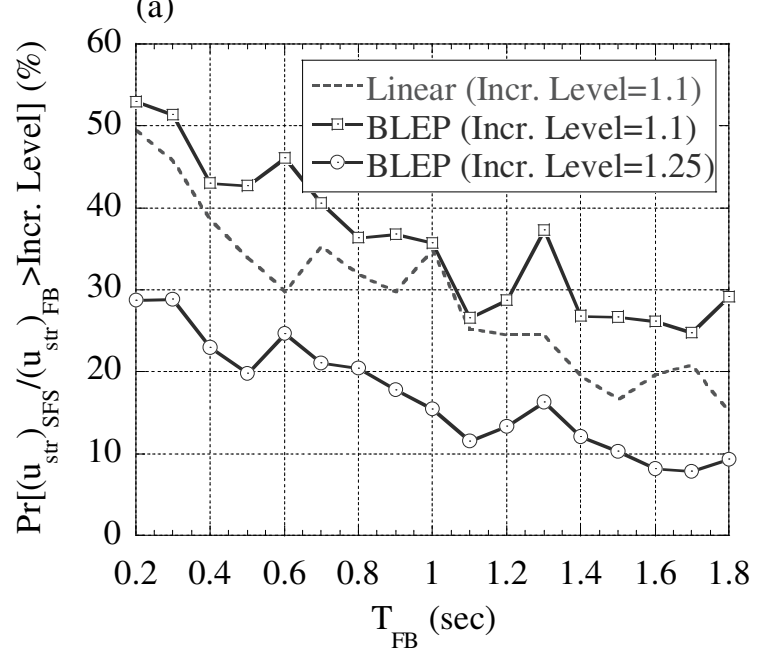

(b)

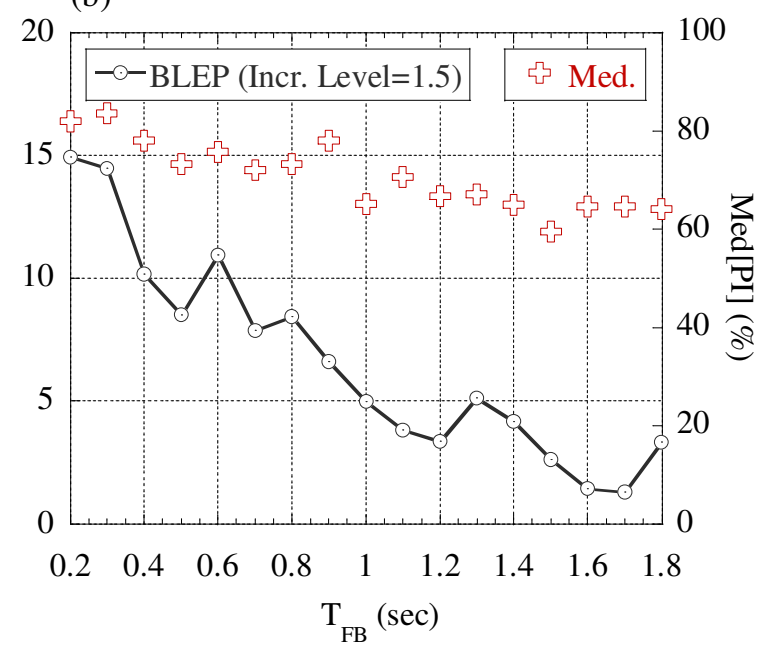

Figure 16. Structural total displacement stochastic amplification spectrum: (a) for $10 \%$ and $25 \%$ of increase, (b) for $50 \%$ of increase in structural response 
(a)

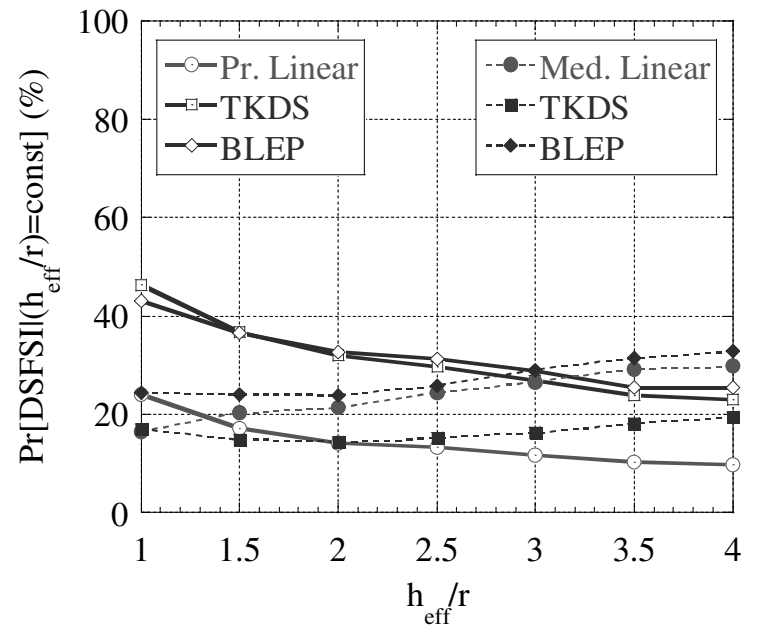

(b)

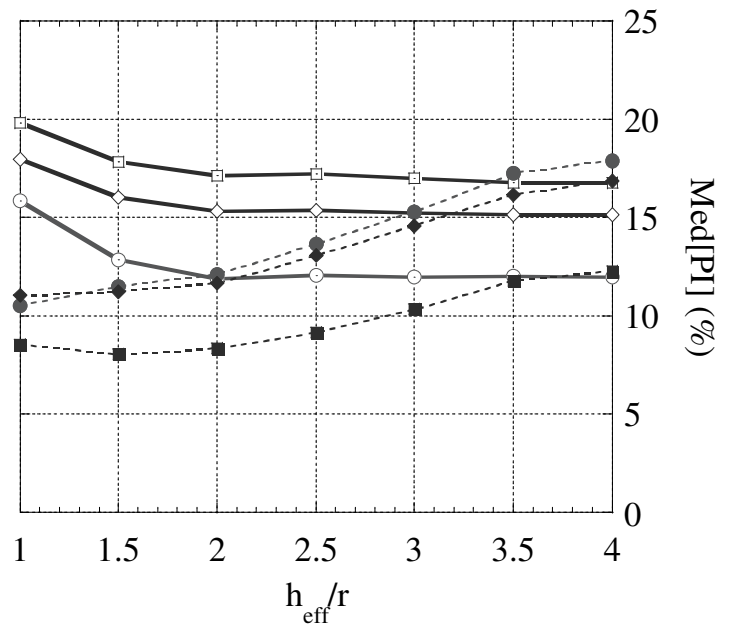

Figure 17. Quantification of DSFSI scenarios based on variation of $\tilde{h}=h_{\text {eff }} / r:$ (a) amplification in structural distortion and (b) amplification in structural total displacement 
(a)

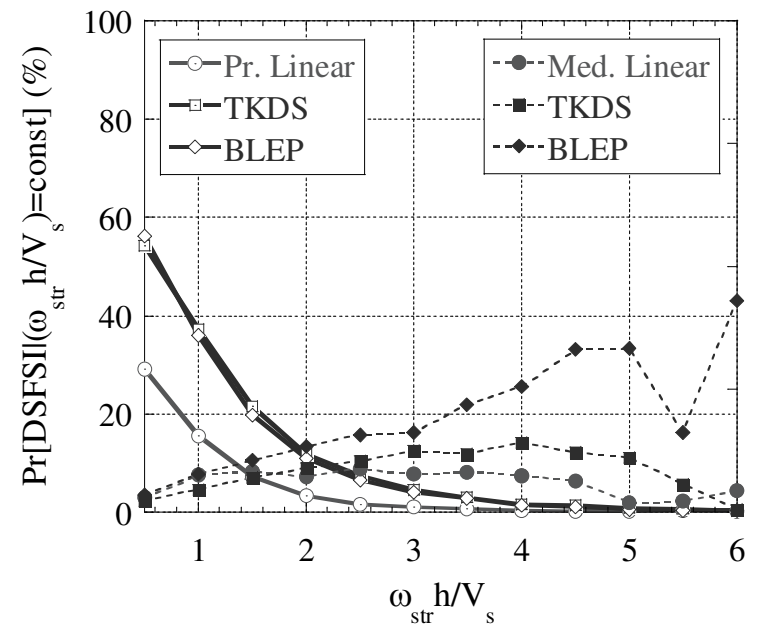

(b)

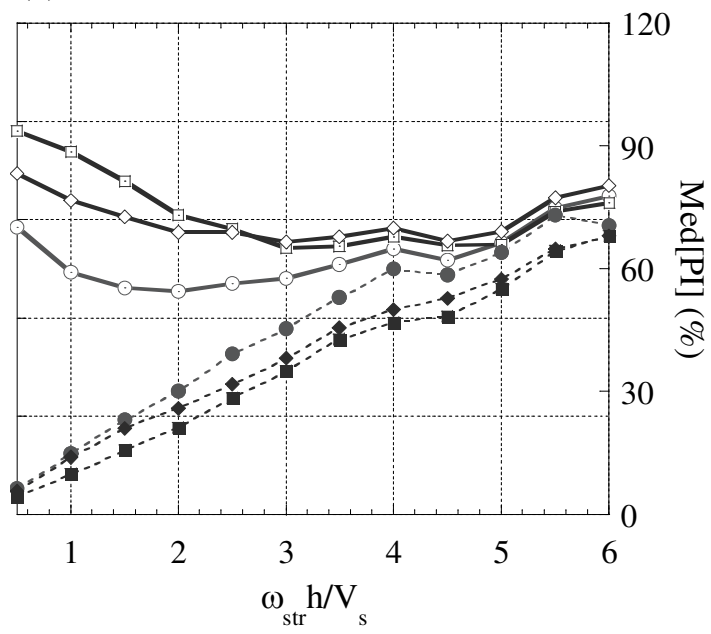

Figure 18. Quantification of DSFSI scenarios based on variation of $\widetilde{\omega}=\omega_{s t r} h / V_{s}:$ (a) amplification in structural distortion and (b) amplification in structural total displacement 
Table 1. Properties of a soil-foundation element based on the cone model concept

\begin{tabular}{|c|c|c|c|c|}
\hline \multicolumn{2}{|c|}{ Motion } & Stiffness & Viscous damping & Added mass \\
\hline \multicolumn{2}{|c|}{ Horizontal } & $\mathrm{k}_{0}=\frac{8 \mathrm{Gr}}{2-\mathrm{v}}$ & $c_{0}=\rho V_{s} A$ & - \\
\hline \multirow{5}{*}{$\begin{array}{l}\stackrel{b 0}{\Xi} \\
\stackrel{\Xi}{0} \\
\stackrel{0}{0}\end{array}$} & $v \leq 1 / 3$ & \multirow{2}{*}{$\mathrm{k}_{\varphi}=\frac{8 \mathrm{Gr}^{3}}{3(1-v)}$} & $\mathrm{c}_{\varphi}=\rho \mathrm{V}_{\mathrm{p}} \mathrm{I}_{\mathrm{r}}$ & - \\
\hline & $1 / 3 \leq v \leq 1 / 2$ & & $c_{\varphi}=\rho\left(2 V_{s}\right) I_{r}$ & $\Delta \mathrm{m}_{\varphi}=1.2(v-1 / 3) \rho \mathrm{I}_{\mathrm{r}} \mathrm{r}$ \\
\hline & \multicolumn{4}{|c|}{ Internal mass moment of inertia } \\
\hline & $v \leq 1 / 3$ & \multicolumn{3}{|c|}{$\mathrm{m}_{\varphi}=\frac{9 \pi}{32} \rho \mathrm{I}_{\mathrm{r}} \mathrm{r}(1-v)\left(\frac{\mathrm{V}_{\mathrm{p}}}{\mathrm{V}_{\mathrm{s}}}\right)^{2}$} \\
\hline & $1 / 3 \leq v \leq 1 / 2$ & \multicolumn{3}{|c|}{$\mathrm{m}_{\varphi}=\frac{9 \pi}{8} \rho \mathrm{I}_{\mathrm{r}} \mathrm{r}(1-v)$} \\
\hline \multirow{2}{*}{\multicolumn{2}{|c|}{ Material damping }} & \multicolumn{3}{|c|}{ Additional parallel connected element $(i=0$ or $\varphi$ ) } \\
\hline & & \multicolumn{2}{|c|}{$\begin{array}{c}\text { Viscous damping to stiffness } \mathrm{k}_{\mathrm{i}} \\
\overline{\mathrm{c}}_{\mathrm{i}}=2 \mathrm{k}_{\mathrm{i}}\left(\xi_{0} / \omega_{0}\right)\end{array}$} & Inertial mass to damping $c_{i}$ \\
\hline
\end{tabular}

The parameters utilised in this table are defined as:

- $\mathbf{r}, \mathbf{A}$ and $\mathbf{I}_{\mathbf{r}}$ : Equivalent radius of the foundation, area of the foundation $\left(\mathrm{A}=\pi \mathrm{r}^{2}\right)$ and mass moment of inertia for rocking motion $\left(\mathrm{I}_{\mathrm{r}}=\pi \mathrm{r}^{4} / 4\right)$

- $\boldsymbol{\rho}, \mathbf{v}, \mathbf{V}_{\mathbf{s}}, \mathbf{V}_{\mathbf{p}}$ and $\mathbf{G}$ : Soil mass density, Poisson's ratio, soil shear wave velocity, soil longitudinal wave velocity and soil shear modulus

- $\xi_{0}$ and $\omega_{0}$ : Equivalent soil material damping and effective frequency of SFS system 